\title{
Long-term persistence of supernumerary B chromosomes in multiple species of Astyanax fish
}

Duílio Mazzoni Zerbinato de Andrade Silva ${ }^{1+}$ (D), Francisco J. Ruiz-Ruano $2,3,4^{*}+\left(\mathbb{D}\right.$, Ricardo Utsunomia $^{5,6}$ (D), María Martín-Peciña ${ }^{3}$, Jonathan Pena Castro ${ }^{7,8}$ (D) Paula Paccielli Freire ${ }^{1,9}$ (D) , Robson Francisco Carvalho ${ }^{1}$ (D) Diogo T. Hashimoto ${ }^{10}\left(\mathbb{D}\right.$, Alexander Suh $^{2,4}$ (D), Claudio Oliveira ${ }^{1}$ (D) Fábio Porto-Foresti ${ }^{6}(\mathbb{D}$, Roberto Ferreira Artoni ${ }^{7,8}$ (D), Fausto Foresti ${ }^{1}$ and Juan Pedro M. Camacho ${ }^{3^{*}}$ (D)

\begin{abstract}
Background: Eukaryote genomes frequently harbor supernumerary B chromosomes in addition to the "standard" A chromosome set. B chromosomes are thought to arise as byproducts of genome rearrangements and have mostly been considered intraspecific oddities. However, their evolutionary transcendence beyond species level has remained untested.

Results: Here we reveal that the large metacentric B chromosomes reported in several fish species of the genus Astyanax arose in a common ancestor at least 4 million years ago. We generated transcriptomes of $A$. scabripinnis and $A$. paranae $O B$ and $1 B$ individuals and used these assemblies as a reference for mapping all gDNA and RNA libraries to quantify coverage differences between B-lacking and B-carrying genomes. We show that the B chromosomes of $A$. scabripinnis and A. paranae share 19 protein-coding genes, of which 14 and 11 were also present in the B chromosomes of $A$. bockmanni and A. fasciatus, respectively. Our search for B-specific singlenucleotide polymorphisms (SNPs) identified the presence of B-derived transcripts in B-carrying ovaries, $80 \%$ of which belonged to nobox, a gene involved in oogenesis regulation. Importantly, the B chromosome nobox paralog is expressed $>30 \times$ more than the $A$ chromosome paralog. This indicates that the normal regulation of this gene is altered in B-carrying females, which could potentially facilitate B inheritance at higher rates than Mendelian law prediction.

Conclusions: Taken together, our results demonstrate the long-term survival of B chromosomes despite their lack of regular pairing and segregation during meiosis and that they can endure episodes of population divergence leading to species formation.
\end{abstract}

Keywords: B chromosomes, Astyanax, Evolution, Genomics, Transcriptomics

\footnotetext{
*Correspondence: francisco.ruiz-ruano@ebc.uu.se; jpmcamac@ugr.es

${ }^{\dagger}$ Duílio Mazzoni Zerbinato de Andrade Silva and Francisco J. Ruiz-Ruano contributed equally to this work.

2Department of Organismal Biology - Systematic Biology, Evolutionary

Biology Centre, Uppsala University, SE-752 36 Uppsala, Sweden

${ }^{3}$ Departamento de Genética, Universidad de Granada, 18071 Granada, Spain

Full list of author information is available at the end of the article
}

(C) The Author(s). 2021 Open Access This article is licensed under a Creative Commons Attribution 4.0 International License, which permits use, sharing, adaptation, distribution and reproduction in any medium or format, as long as you give appropriate credit to the original author(s) and the source, provide a link to the Creative Commons licence, and indicate if changes were made. The images or other third party material in this article are included in the article's Creative Commons licence, unless indicated otherwise in a credit line to the material. If material is not included in the article's Creative Commons licence and your intended use is not permitted by statutory regulation or exceeds the permitted use, you will need to obtain permission directly from the copyright holder. To view a copy of this licence, visit http://creativecommons.org/licenses/by/4.0/. The Creative Commons Public Domain Dedication waiver (http://creativecommons.org/publicdomain/zero/1.0/) applies to the data made available in this article, unless otherwise stated in a credit line to the data. 


\section{Background}

Thousands of eukaryotic species harbor dispensable B chromosomes which perpetuate in natural populations as genomic parasites $[1,2]$. Recent research has shown that B chromosomes usually carry redundant genetic information already present on the standard (A) chromosomes [3-6]. The most remarkable exception is the paternal sex ratio (PSR) B chromosome in the wasp Nasonia vitripennis, which carries one gene (named haploidizer), which does not match to any sequence in standard (A) chromosomes [7]. In some cases, B chromosomes might have become useful elements for the host genome, as reported in the fungus Nectria haematococca where B chromosomes carry genes determining pathogenicity to pea [8]. In other cases, the possible evolution of $\mathrm{Y}$ chromosomes from pre-existing B chromosomes was suggested in the homopteran Rhinocola aceris and Cacopsylla peregrina [9, 10], and a similar derivation has been claimed for the germline-restricted chromosomes in songbirds [11]. B chromosomes are usually polymorphic within populations, but apparently similar Bs have been found in several closely related species, suggesting that they persisted across speciation events [12].

The genus Astyanax Baird \& Girard is widely distributed from southern USA to central Argentina [13]. It includes about 200 species thus being one of the most diverse genera within the Characiformes order [14]. Recently, based on phylogenetic analysis performed using Cytochrome C Oxidase subunit I (COI) sequences, Rossini et al. [15] separated the Astyanax genus into five clades, with Clade 1 including A. scabripinnis, A. paranae, A. bockmanni, and A. fasciatus. Among them, the first two belong to the $A$. scabripinnis species complex [16]. Within the genus, 11 species carry B chromosomes of various sizes and morphologies, of which seven species belonging to the Clade 1 contain large metacentric B chromosomes [17-40] (Additional file 1: Table S1). This prevalence among species led Moreira-Filho et al. [39] to suggest the common origin of B chromosomes in several Astyanax species, and this has been supported by evidence from repetitive DNA content [41]. However, similarity in B chromosome morphology and size, chromosome banding, and satellite DNA location might simply be the result of convergent evolution instead of common descent.

The recent finding that B chromosomes can harbor protein-coding genes (for instance, see NavarroDominguez et al. [6]) provides a direct test for the common descent hypothesis, since the likelihood of finding the same gene content for B chromosomes of different species by chance is negligible. Here we analyze the protein-coding gene content of the large metacentric B chromosomes in A. scabripinnis, A. paranae, A. bockmanni, and A. fasciatus by comparing genomic and transcriptomic Illumina data between 1B (with B chromosomes) and $\mathrm{OB}$ (without $\mathrm{B}$ chromosome) individuals for the two first sister species and by means of qPCR in the four species. We found that the large metacentric $B$ chromosomes reported in these fish species most likely arose in a common ancestor at least 4 million years ago. In addition, the transcription of some cell cycle gene paralogs residing on these $\mathrm{B}$ chromosomes could potentially facilitate their drive during cell division. The extended permanence of $\mathrm{B}$ chromosomes in Astyanax species demonstrates the capacity of B chromosomes to resist population differentiation during speciation.

\section{Results}

\section{Identifying B-linked genes}

We performed cytogenetic analyses prior to the Illumina sequencing and GPCR validation to determine the presence or absence of the large metacentric B chromosomes in the individuals of the four species analyzed here, as reported in previous studies (Table S1). The general pipeline of this work is summarized in Fig. 1. We first built a de novo transcriptome with a total of 16 female RNA libraries: four in A. scabripinnis (ovaries from two $\mathrm{OB}$ and two $1 \mathrm{~B}$ individuals) and 12 in A paranae (ovaries and muscle from three $\mathrm{OB}$ and three $1 \mathrm{~B}$ individuals). We used this de novo transcriptome assembly as a reference for mapping all gDNA and RNA libraries to quantify coverage differences between B-lacking and Bcarrying genomes. After mapping and copy number calculation, a total of 40,697 transcriptome contigs showed mappings of gDNA reads on them. Then we discarded all contigs showing more than four genomic copies (as they might be highly repetitive elements) and those showing less than 0.5 copies (since they might have had mapping errors) in the B-lacking genomes. The remaining 33,297 and 32,844 contigs showing mappings in A. scabripinnis and A. paranae, respectively, were then analyzed for overabundance in the B-carrying libraries with respect to the B-lacking ones. Assuming the presence of one gene copy per A or B chromosome, we calculated a theoretical minimum threshold that a transcriptome contig should pass to suggest the presence of one (or more) extra (paralogous) copy(s) on the B chromosome, in terms of the fold change in genomic coverage ( $\mathrm{gFC}$ ) attributable to $\mathrm{B}$ presence: $\mathrm{gFC}=\log _{2}$ $(1.5) \geq 0.585$, where 1.5 is the quotient between copy numbers in the $1 \mathrm{~B}$ and $\mathrm{OB}$ genomes ( 3 copies in $1 \mathrm{~B}, 2$ copies in $0 \mathrm{~B})$. In A. scabripinnis, we had gDNA libraries from three $0 \mathrm{~B}$ and three $1 \mathrm{~B}$ individuals, so that we calculated gFC for each B-carrying individual (by dividing its copy number by the average of the three B-lacking individuals) and selected those contigs showing gFC $\geq 0.585$ in all three B-carrying individuals as candidates for being 


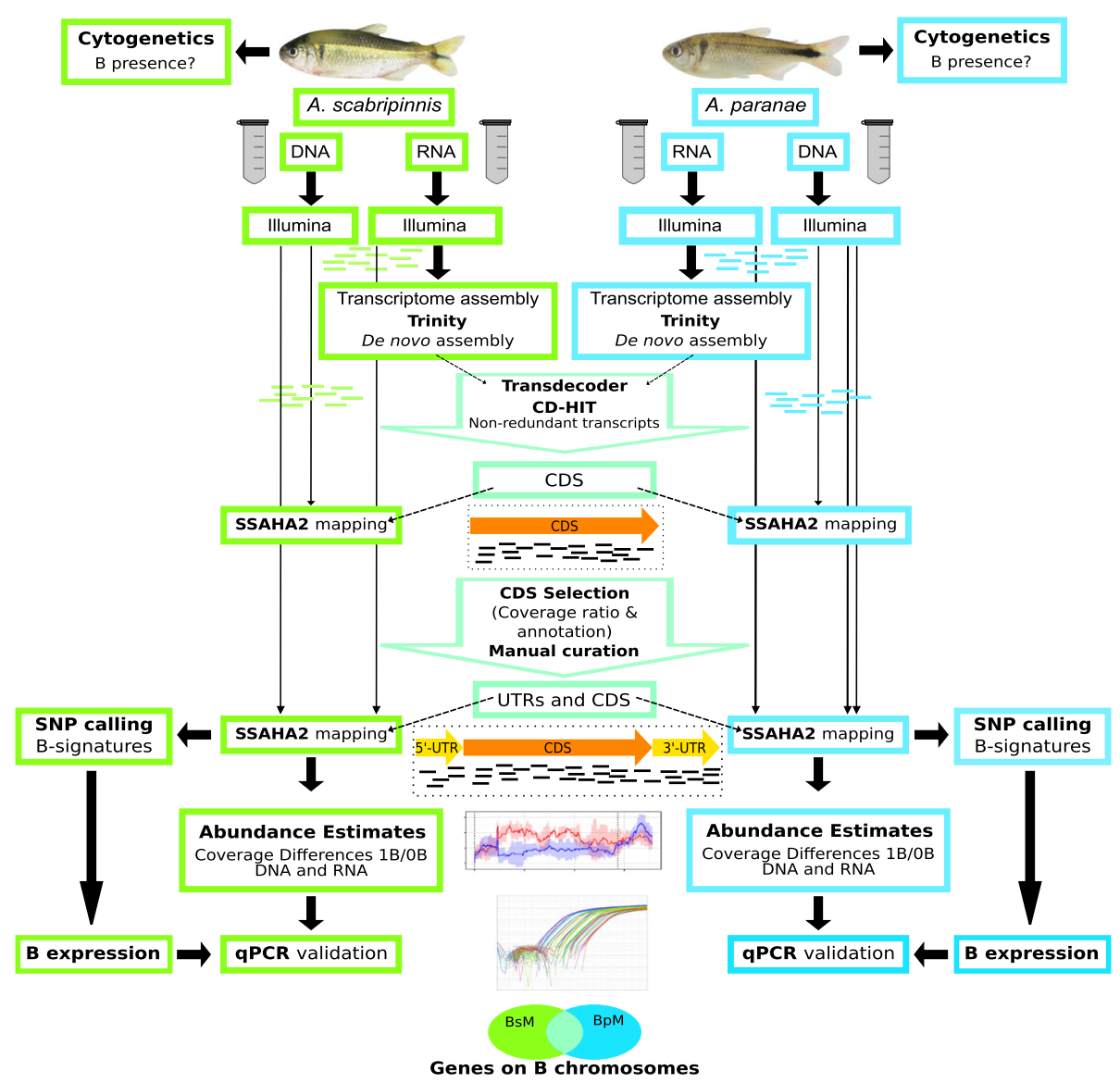

Fig. 1 Bioinformatic protocol applied for the analysis of gene coverage, gene selection, and SNP calling. See Methods for details

B-linked (genes present on B chromosome, but not exclusively) (Fig. 2, Additional file 2: Dataset 1). In $A$. paranae, however, we had Illumina libraries from only one B-carrying and one B-lacking individual, and thus increased the threshold to $\mathrm{gFC} \geq 1.0$ to limit the number of false positives.

This analysis of gFC, performed on the Illumina Bcarrying and B-lacking gDNA libraries, revealed 431 contigs showing gFC $\geq 0.585$ in A. scabripinnis (Additional file 2: Dataset 1.5a) and 377 contigs showing gFC $\geq 1.0$ in $A$. paranae (Additional file 2: Dataset 1.5b). Annotation revealed that 227 contigs being candidate to be B-linked in A. scabripinnis corresponded to 211 protein-coding genes, with some contigs belonging to the same gene. Similarly, in A paranae 257 contigs corresponded to 234 protein-coding genes. Remarkably, 34 contigs corresponding to protein-coding genes found in the former species were also present in A. paranae (15\%), a result that cannot be explained by chance, as shown by the binomial likelihood calculated for 15 coincidences and 85 differences (out of 100) with $p=1 / 25$ for coincidence (since the haploid chromosome number is 25 in these species) and $q=24 / 25$ for difference $(P=$ $\left.8.47 \times 10^{-6}\right)$. Note that this probability was calculated for the percent coincidences to circumvent the spreadsheet problem to calculate factorial numbers higher than 170, and our sample consisted of 227 contigs. In addition, the correlation between gFC values for these 34 contigs in both species was highly positive $(r s=0.87$, $t=9.92, P<0.000001)$ indicating very high correspondence in their presence in B-carrying libraries of both species (Fig. 3, Additional file 2: Dataset 1.6).

We then chose 27 candidate B-linked genes for qPCR validation (see the criteria in Methods) with primers designed in exons of the gene with high coverage in the $1 \mathrm{~B}$ individuals comparing the $\mathrm{OB}$ ones (Fig. 4a). This qPCR analysis revealed that 21 genes showed higher abundance in 1B gDNA libraries, of which 19 genes were higher in 1B individuals of both species (Table 1, Additional file 1: Table S2). The six remaining genes failed to show overabundance in $1 \mathrm{~B}$ individuals from either species (Additional file 1: Table S3). Of note, the paired mean differences in the relative quantification (RQ) effect size due to $B$ presence were strongly positively correlated between species (Spearman $r \mathrm{~s}=0.934, t=13.08, \quad P<$ 0.000001 ), supporting a high similarity in quantitative 


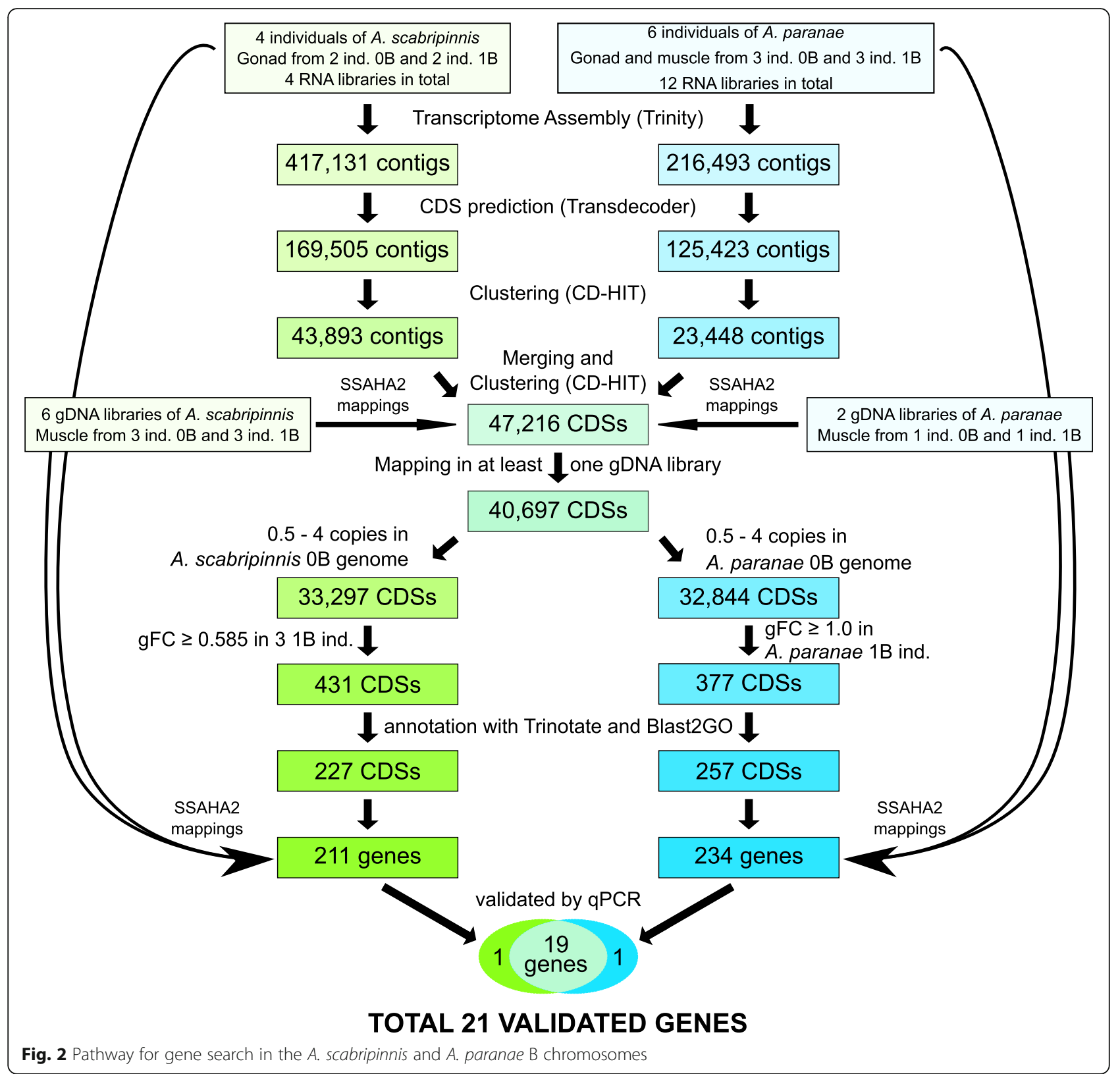

overabundance due to $\mathrm{B}$ presence in both species. We then searched for our $21 \mathrm{~B}$-linked genes on the $\mathrm{B}$ chromosomes of two additional Astyanax species (A. bockmanni and $A$. fasciatus) to test the hypothesis of their common descent, comparing copy number between $1 \mathrm{~B}$ and $\mathrm{OB}$ individuals via $\mathrm{qPCR}$ on gDNA. The Gardner-Altman plot test [42] indicated that 14 of these genes in A. bockmanni and 11 in A. fasciatus are also B-linked (Fig. 4b, Additional file 1: Table S3).

Most qPCR-validated genes showed high gFC values, whereas most genes failing it showed low ones (see Table 1). Specifically, 17 out of the 18 genes showing $\mathrm{gFC} \geq 1$ in $A$. paranae were $\mathrm{qPCR}$ validated, as well as three genes (amhr2, bt1a1 and hem2) failing to meet this condition. In fact, the gFC of amhr2 and hem 2 were about 0.9 , thus being close to the threshold employed in this species (gFC $\geq 1)$ (Table 1). In A. scabripinnis, the 20 genes that were qPCR-validated showed $\mathrm{gFC} \geq 0.585$ in all three B-carrying individuals analyzed, but no gene that failed to meet this condition was validated. These results indicate that gFC analysis is highly useful to perform efficient search for B chromosome genes and that using more biological replicates increases the efficiency of the B-linked gene selection method based on gFC. As a negative control, we also tried to $\mathrm{qPCR}$ validate the low coverage (LC) regions in four genes showing the IC pattern (amhr2, numa1, sbno2, and simc1). In $A$. scabripinnis, $A$. paranae, and $A$. fasciatus, all four genes 

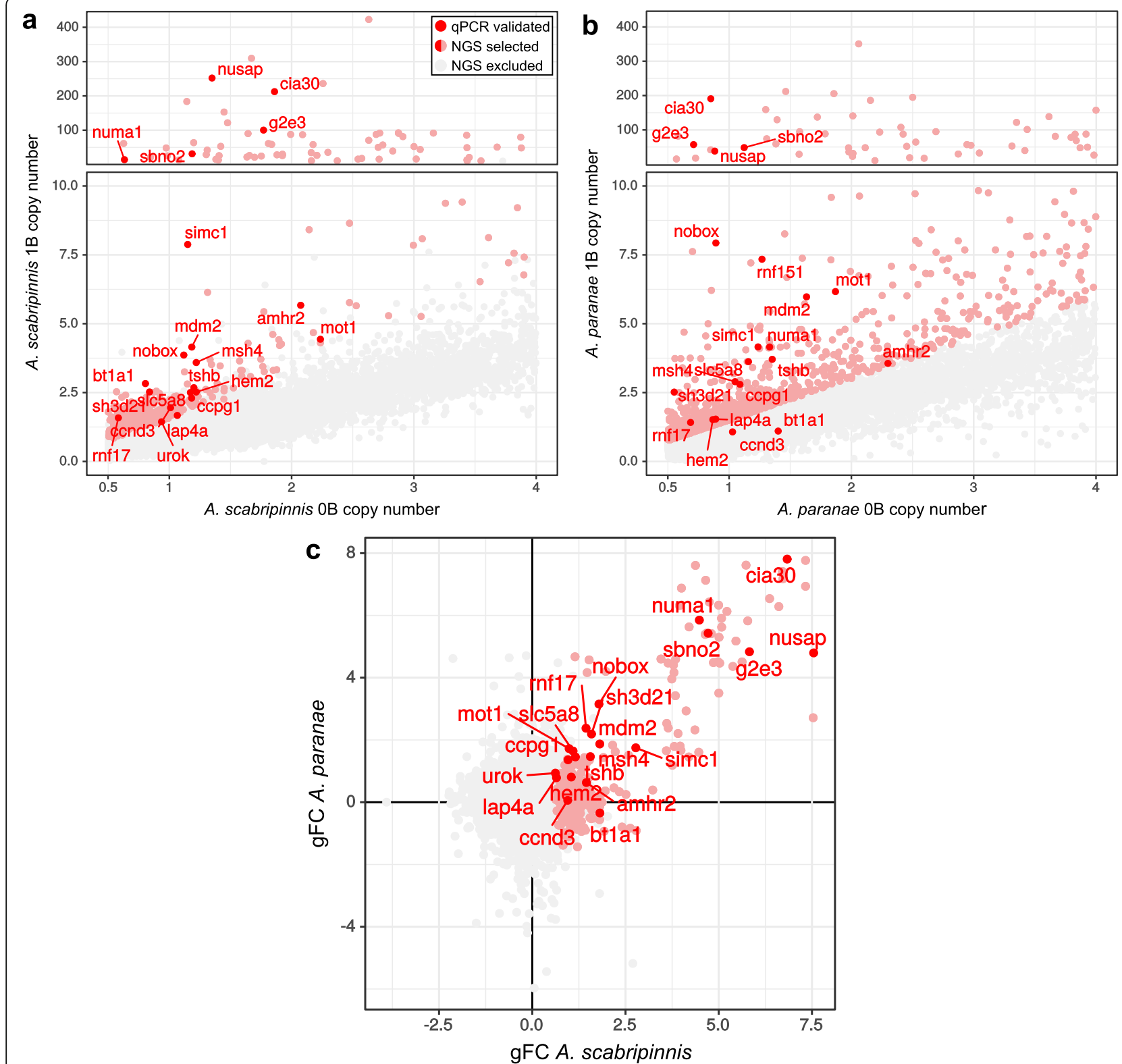

Fig. 3 Detection of protein-coding genes residing in the B chromosomes of Astyanax scabripinnis and A. paranae. a Detection of protein-coding genes in the B chromosome of Astyanax scabripinnis by mapping gDNA Illumina reads obtained from three B-carrying (1B) and three B-lacking $(O B)$ individuals on a de novo transcriptome built with Illumina reads coming from ovary RNA libraries from two individuals. Scatter plot showing the mean copy number for 47,216 CDSs in OB and 1B females. The CDSs which, in presence of one B chromosome, showed a genomic fold change $\left[\mathrm{gFC}=\log _{2}(1 \mathrm{~B} / \mathrm{OB})\right]$ higher than 0.585 in the three B-carrying individuals (431 contigs in total, see Supplementary Table 11) are shown in light red color, and those failing to reach this threshold are noted in gray color. In addition, the 21 protein-coding genes which were validated by qPCR in A. scabripinnis and A. paranae are noted in dark red color for the contig showing the highest gFC value. $\mathbf{b}$ Distribution of coverage in copy numbers for CDSs in $1 \mathrm{~B}$ and $\mathrm{OB}$ individual in A. paranae. Light red indicates the 2019 out of 32,830 CDSs with gFC in A. paranae higher than 0.585 and dark red indicated the 21 genes validated with GPCR. Note that only bt1al and ccnd 3 genes do not meet the gFC criteria, but bt1a1 was validated in these species using PCR. c Protein-coding gene content of the B chromosomes is highly similar among species. The figure shows the comparison of gFC values between A. scabripinnis and A. paranae for the CDS meeting the copy number criteria in A. scabripinnis OB individuals. The $\mathrm{gFC}$ values found for the $21 \mathrm{~B}$ chromosome genes found in both species were positively correlated (Spearman rank correlation: $r s=0.27, t=3.11, P=0.002$ ). Color patterns coincide with those in panel $\mathbf{a}$

failed to show overabundance for the LC region in Bcarrying individuals (Additional file 1: Table S3). In A. bockmanni, however, the LC regions of the amhr2 and sbno2 genes also showed higher coverage in B-carrying individuals, indicating some differences in gene coverage patterns between the B chromosomes in these species. 


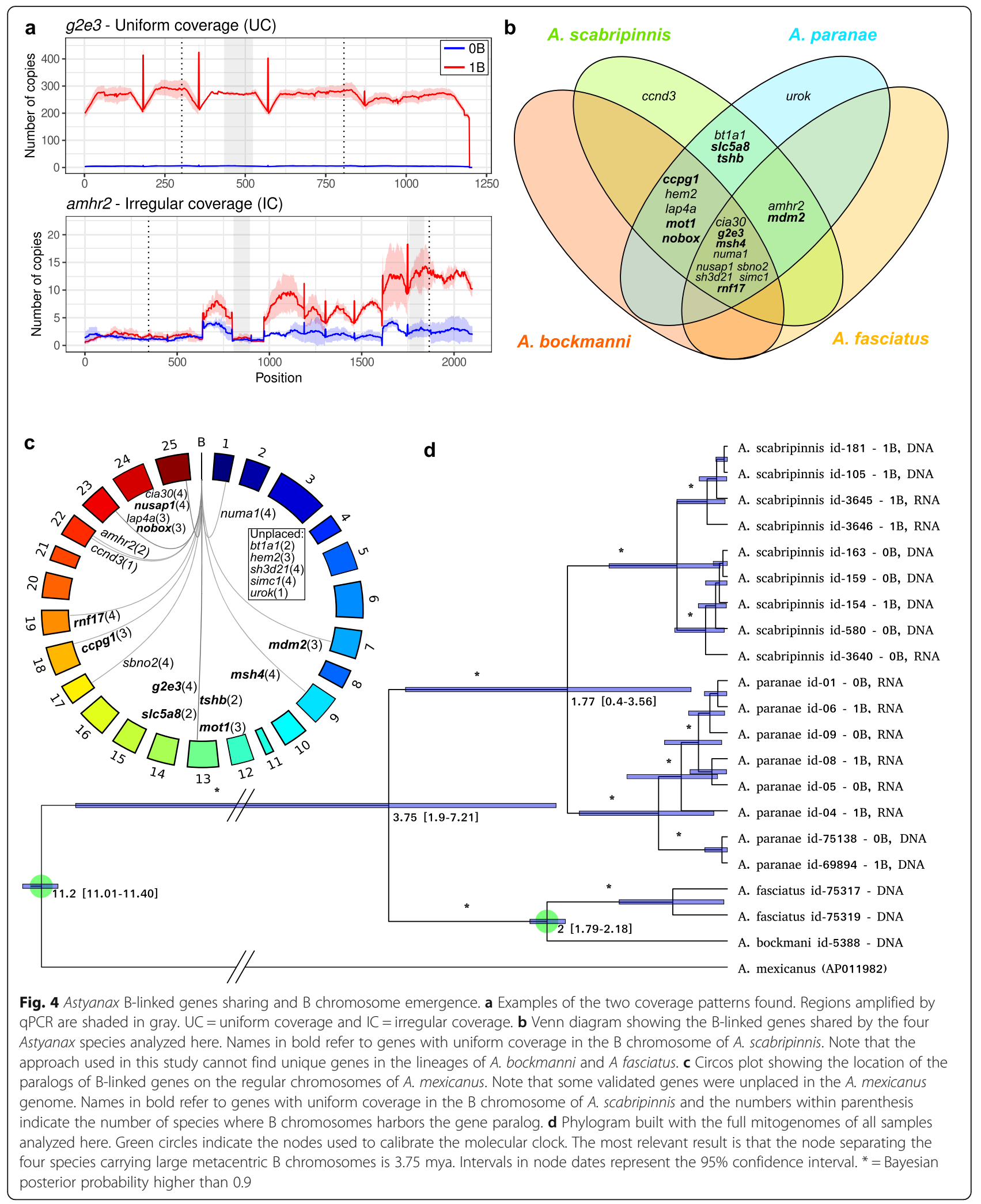


Table 1 Identification, validation, and function of 21 protein-coding genes in the B chromosomes from the studied species

\begin{tabular}{|c|c|c|c|c|c|c|c|c|}
\hline \multirow[b]{2}{*}{ Gene } & \multicolumn{3}{|c|}{ A. scabripinnis } & \multicolumn{2}{|c|}{ A. paranae } & \multicolumn{2}{|l|}{ qPCR } & \multirow[b]{2}{*}{ Function } \\
\hline & $\mathrm{gFC}$ & qPCR & SNPs & $\mathrm{gFC}$ & qPCR & A. bockmanni & A. fasciatus & \\
\hline$a m h r 2$ & 1.8 & 1 & 7 & 0.9 & 1 & 0 & 1 & Gonadal development \\
\hline btlal & 1.7 & 1 & 0 & -0.4 & 1 & 0 & 0 & Unknown \\
\hline cend3 & 1.2 & 1 & 0 & -0.1 & 0 & 0 & 0 & Cell cycle \\
\hline ccpgl & 0.9 & 1 & 9 & 1.3 & 1 & 1 & 0 & Cell cycle \\
\hline cia30 & 7.0 & 1 & 0 & 7.9 & 1 & 1 & 1 & Mitochondrial \\
\hline g2e3 & 5.7 & 1 & 0 & 5.0 & 1 & 1 & 1 & Cell cycle \\
\hline hem2 & 1.8 & 1 & 3 & 0.9 & 1 & 1 & 0 & Biosynthesis \\
\hline lap $4 a$ & 1.5 & 1 & 0 & 1.1 & 1 & 1 & 0 & Transport \\
\hline$m d m 2$ & 2.0 & 1 & 0 & 1.9 & 1 & 0 & 1 & Indirect cell cycle regulation \\
\hline mot1 & 1.0 & 1 & 1 & 1.6 & 1 & 1 & 0 & Transport \\
\hline msh4 & 1.6 & 1 & 21 & 1.4 & 1 & 1 & 1 & Cell cycle \\
\hline nobox & 1.7 & 1 & 5 & 3.1 & 1 & 1 & 0 & Cell cycle \\
\hline numal & 2.7 & 1 & 0 & 2.5 & 1 & 1 & 1 & Cell cycle \\
\hline nusap1 & 7.3 & 1 & 0 & 3.9 & 1 & 1 & 1 & Cell cycle \\
\hline$r n f 17$ & 1.3 & 1 & 2 & 1.9 & 1 & 1 & 1 & Indirect cell cycle regulation \\
\hline sbno2 & 5.9 & 1 & 0 & 6.8 & 1 & 1 & 1 & Transcriptional coregulator \\
\hline $\operatorname{sh} 3 d 21$ & 1.5 & 1 & 34 & 1.6 & 1 & 1 & 1 & Unknown \\
\hline $\operatorname{simcl}$ & 3.1 & 1 & 25 & 2.0 & 1 & 1 & 1 & Transcription factor \\
\hline s/c5a8 & 1.0 & 1 & 5 & 1.6 & 1 & 0 & 0 & Transport \\
\hline tshb & 0.7 & 1 & 2 & 1.7 & 1 & 0 & 0 & Hormone-mediated signaling pathway \\
\hline urok & 0.4 & 0 & 0 & 2.3 & 1 & 0 & 0 & Plasminogen activation \\
\hline Sum & & 20 & 114 & & 20 & 14 & 11 & \\
\hline
\end{tabular}

NGS analyses were performed for the large metacentric of $A$. scabripinnis and $A$. paranae, and, additionally, qPCR tests for their presence on $\mathrm{B}$ chromosomes in $A$. bockmanni and $A$. fasciatus. Genomic fold change $(\mathrm{gFC})$ was calculated as $\log _{2}(1 \mathrm{~B} / 0 \mathrm{~B})$ of mean nucleotide coverage along transcript length in the $1 \mathrm{~B}$ and $0 \mathrm{~B}$ libraries. In the qPCR columns, 1 indicates $\mathrm{QPCR}$ validation of gene overabundance in $1 \mathrm{~B}$ genomes compared to $\mathrm{OB}$ ones

\section{Non-random coincidences in gene content between species}

Given that Astyanax genomes contain about 25 chromosome pairs, the probability for a given gene to be contained in an extra chromosome is $1 / 25=0.04$, assuming that all chromosomes are of equal size (which clearly is not true, although for the average genome this may be a valid assumption). Using this estimate, we found that the binomial likelihood that $\mathrm{B}$ chromosomes in A. paranae, $A$. bockmanni, and A. fasciatus would carry, by chance, 19, 14 , or 11 protein-coding genes, respectively, out of the 21 found in the $\mathrm{B}$ chromosome of $A$. scabripinnis, was extremely low $\left(5.3 \times 10^{-25}, 2.3 \times 10^{-15}\right.$, and $\left.9.8 \times 10^{-11}\right)$. Therefore, the gene content similarity between the B chromosomes of these four species cannot be explained by chance.

\section{Origin of the B chromosome}

We investigated whether B chromosomes in the four species analyzed here were inherited from a common ancestor species. Under this hypothesis, we should expect that the overlap in gene content between $B$ chromosomes in the four Astyanax species is inversely proportional to the time since they shared their last common ancestor. To test this hypothesis, we assembled the full mitogenome sequence in the four species and built a phylogenetic tree using the $A$. mexicanus mitogenome as outgroup (Fig. 4d). We then performed a cluster analysis with the binary information of gene content overlap between the four species (see Additional file 1: Table S3) and extracted the matrix of Euclidean distances. Finally, a Mantel test showed a highly positive correlation between the matrices of $p$ distances for mitogenome sequences and Euclidean distances for $\mathrm{B}$ chromosome gene content $(r=0.865, P=0.043$, based on 10,000 replicates). This indicated that B chromosome gene content is consistent with the phylogenetic relationships of these species, strongly suggesting that the $\mathrm{B}$ chromosome arose in a common ancestor of all four species, roughly 4 mya.

It is important to note that our results could also be compatible with recurrent $\mathrm{B}$ chromosome emergence in different species. As recent research has revealed that $\mathrm{B}$ chromosomes appear to be composed of DNA 
sequences acquired from many different A chromosomes [3], we investigated this possibility by mapping the $21 \mathrm{~B}$-linked genes on the A. mexicanus A chromosomes (NCBI Genome assembly accession number GCA_000372685.2 [43]). We found 16 of these genes located on ten different chromosomes (Fig. 4c), making it unlikely that $\mathrm{B}$ chromosomes would have received the same genes from the same A chromosomes independently in the four species. Moreover, it was remarkable that incomplete genes missed exactly the same regions in different species, a fact that would be more parsimoniously explained through common descent (Additional file 1: Table S3).

\section{Expression of B-linked genes}

We next identified B-specific SNPs for the 19 B-linked genes found in both $A$. scabripinnis and A. paranae (Additional file 1: Table S4), which we designated as Alt (alternative sequence variants) to differentiate them from the reference (Ref) variants found in the OB libraries. We found 114 Alt variants in 11 genes, 106 of which showed counts in both species (Additional file 1: Tables S4, S5).

We also performed differential expression analysis in A. scabripinnis (ovaries from two $\mathrm{OB}$ and two $1 \mathrm{~B}$ females) and $A$. paranae (ovaries and muscle from three $\mathrm{OB}$ and three $1 \mathrm{~B}$ females). Transcriptome analysis of these 16 RNA libraries showed that most B paralogs displayed very low expression levels in the ovary, the only exception being the nobox gene which displayed 7.5-13.2-fold higher expression for the B-linked than for the A-linked paralog in A. paranae, and 30.8-fold higher expression in one of the two females analyzed in $A$. scabripinnis (Additional file 1: Table S6). In muscle cells from the same A. paranae females, however, the nobox gene was inactive, as expected for a gene involved in oogenesis regulation. Intriguingly, the msh4 gene showed 5.5-fold higher expression of the B-linked paralog in muscle, but it was observed in only one of the three individuals analyzed. Likewise, in A. scabripinnis, one of the two females analyzed showed no nobox transcription, presumably due to age differences between the two females analyzed (Fig. 5a, Additional file 1: Table S6). These results indicate that most B-linked genes were transcriptionally inactive in the individuals analyzed, although the strength of this conclusion is limited to the tissues, developmental stages, and environmental conditions under which our present experiments were performed. Additional RT-qPCR experiments for the nobox gene in both species showed about 5 -fold effect size (mean differences) for transcription level in Bcarrying ovaries compared to B-lacking ones, only 0.5fold difference in female muscle, and no difference at all in testes (Fig. 5b, Additional file 3: Dataset 2). This result confirmed the upregulation of the nobox gene in the

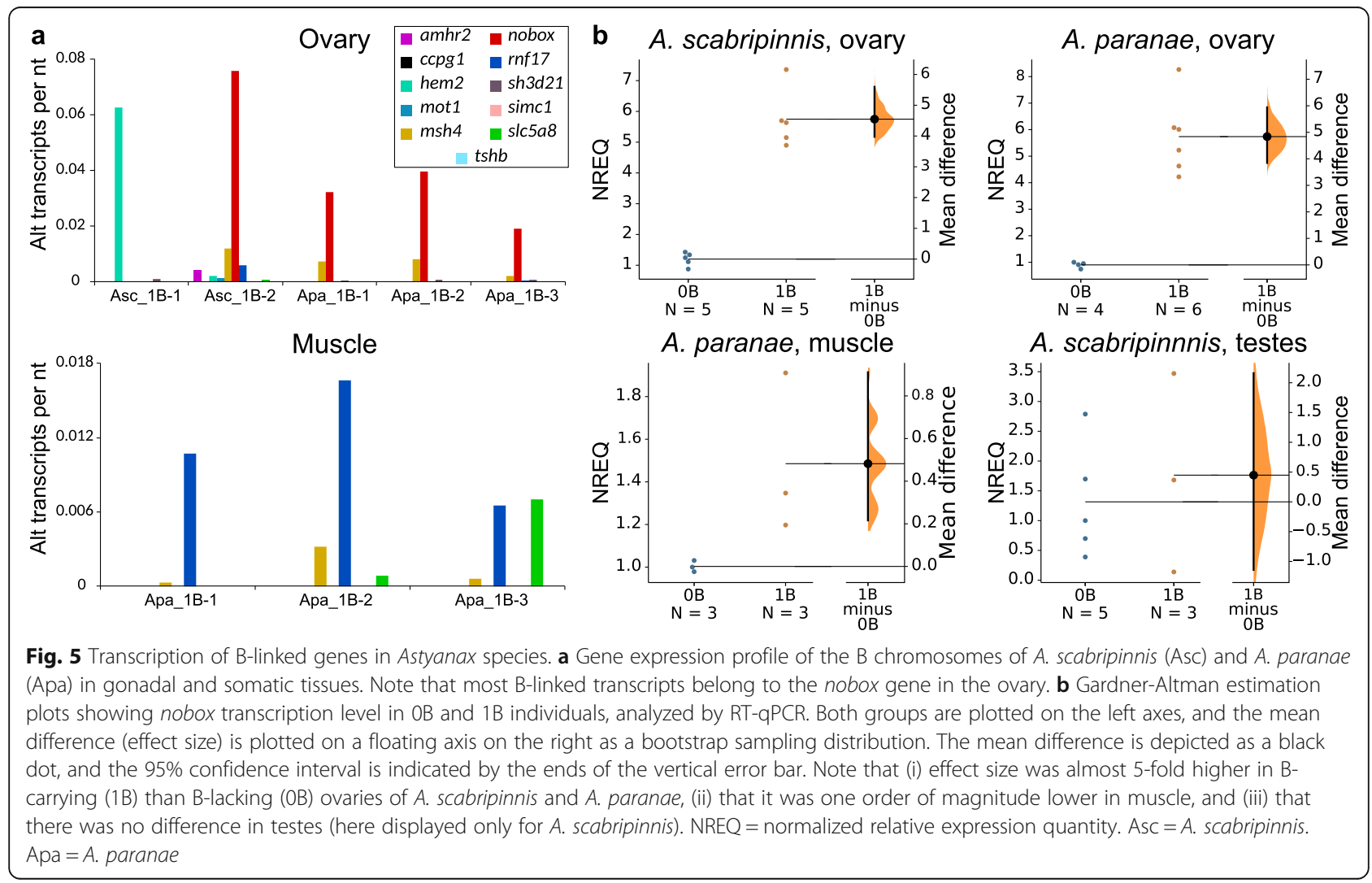


ovaries of B-carrying females, which, as shown above, is due to the active transcription of the B-chromosomal paralogs.

Among the four IC genes, numa1 and sbno 2 did not exhibit B-specific SNPs and we could not analyze Bspecific expression for them (Additional file 1: Table S4) although the gene coverage profiles in B-carrying individuals indicated that the $\mathrm{HC}$ regions showed higher transcription than LC ones (Additional file 4: Dataset 3). In addition, the simc1 gene showed B-specific SNPs but we found no expression for it (Additional file 1: Table S4), suggesting its silencing in the life cycle stages analyzed. Finally, the B-specific SNPs found in the amhr2 gene allowed detecting its expression in the ovary of one $A$. scabripinnis individual, suggesting that it might be a processed pseudogene (Additional file 1: Table S4).

\section{Discussion}

The similarity in gene content for B chromosomes in four Astyanax species and the positive correlation between the matrices of $p$ distances (for mitogenome sequences) and Euclidean distances for gene content suggest their common descent. The lower number of genes shared by the $\mathrm{B}$ chromosomes in A. bockmani and $A$. fasciatus might be due either to their actual absence in the B chromosome of these species, or to the accumulation of sequence differences in the gene regions where the qPCR primers were designed to anchor (which were conserved regions in A. scabripinnis and A. paranae), because of which the primers might have not worked in $A$. bockmani and A. fasciatus. Therefore, the absence of qPCR amplification for certain genes in A. bockmanni and $A$. fasciatus does not allow to rule out the presence of these genes on their B chromosomes, as the DNA sequences on which the PCR primers should have anchored might have changed. In any case, however, the observed differences in the qPCR results make it unlikely that the $\mathrm{B}$ chromosomes of the four species are the result of recent interspecific hybridization, but we cannot still rule out this possibility for the sister species $A$. scabripinnis and $A$. paranae. An example of a supernumerary chromosome arisen through experimental interspecific hybridization was reported by Perfectti and Werren [44] in the parasitic wasps Nasonia vitripennis and $N$. giraulti. In fact, the paternal sex ratio (PSR) chromosome in $N$. vitripennis contains DNA sequences showing higher similarity with those in wasps genus Trichomalopsis than with the A chromosomes from $N$. vitripennis $[7,45]$, suggesting its origin through interspecific hybridization. Interspecifically arisen B chromosomes have also been reported in the gynogenetic fish Poecilia formosa [46], and possible horizontal transfer of B chromosomes between species has also been suggested for the bee genus Partamona [47].
In the case of the four Astyanax species analyzed here, the high similarity in B chromosome gene content cannot be parsimoniously explained by chance or independent origin, whereas the observed differences make recent hybridization unlikely. Therefore, we believe that the most parsimonious explanation is that the $\mathrm{B}$ chromosomes in these four species were inherited from a $B$ that was already present in a common ancestor. Among the genes validated by qPCR, the higher number of coincidences in B-linked gene content between the sister species $A$. scabripinnis and $A$. paranae, and the lower figures observed in A. bockmanni and A. fasciatus, are inversely proportional to the time since they shared their last common ancestor. The phylogenetic tree built with full mitogenomes indicated that the large metacentric $B$ chromosome found in the four species analyzed here arose about 4 mya, i.e., since they split from their common ancestor. Even though our results are consistent with the shared origin of the B chromosomes in the four species, we admit that our experimental design is not ideal, since our reference transcriptome was assembled using the sister species $A$. scabripinnis and $A$. paranae but not included transcriptome or genome analyses in $A$. bockmanni and $A$. fasciatus. The absence of this information precluded species-specific primer design and thus we cannot be sure whether negative qPCR results for some genes in these two species are due to gene absence in their B chromosomes or, as commented above, to sequence divergence in the gene regions were primers were designed to be anchored. A recent study has reported the gene content of $\mathrm{B}$ chromosomes in two more distantly related Astyanax species, namely A. correntinus and $A$. mexicanus [21], but the absence of coincidence with the four species studied here suggests an independent origin for $\mathrm{B}$ chromosomes in these two species.

The long-term persistence of B chromosomes in Astyanax species demonstrates that B chromosomes can endure episodes of population divergence leading to species formation, even though their number is not fixed to one per haploid genome (as standard chromosomes) and they do not have regular meiosis. Our results also indicate that genomes are able to face major evolutionary challenges, such as speciation, in spite of bearing these extra chromosomes. This is also supported by recent research suggesting that all passerine birds carry a germline-restricted chromosome which likely descended from a B chromosome (GRC) [11, 48].

Eight out of the 21 B-linked genes detected here code for functions related to cell cycle regulation and gametogenesis (see Table 1). If active and functional in the right place and time, these eight genes might influence crucial processes for $\mathrm{B}$ chromosome transmission, such as mitosis or meiosis. Unfortunately, B chromosome transmission has not yet experimentally been analyzed in any 
Astyanax species. Two fish species where this has been done gave different results, suggesting the need for caseby-case analysis. No drive was found in Prochilodus lineatus [49-51] whereas micro-B-chromosomes in gynogenetic Poecilia formosa were paternally transmitted through genetic leakage [52]. In addition, Clark and Kocher [53] demonstrated that the B chromosome of the cichlid fish Metriaclima lombardoi exhibits drive, with $70 \%$ average transmission rate, because it carries a female sex determiner. Therefore, although it is conceivable that B chromosomes in Astyanax needed to show some kind of drive for successful passage through several speciation events, its real existence remains a mystery.

A good indication of the potential functional importance of B-linked genes is the degree at which they are transcribed. Based on B-specific sequence signatures, our transcriptome analysis showed that most B chromosome transcripts from the B-linked genes confirmed by qPCR belong to genes with functions related to cell cycle regulation, as would be expected for a parasitic B chromosome trying to manipulate cell divisions. In $A$. scabripinnis, one of the two 1B females showed a completely different transcriptional profile compared with those in the other females analyzed here, due to the fact that it was the only sampled immature female (Fig. 5a). The other female, however, showed a transcriptional profile very similar to that observed in the three $1 \mathrm{~B} A$. paranae females, where about $90 \%$ of transcripts coming from the B chromosome belonged to two cell cycle genes (msh4 and nobox), and more than $85 \%$ of them corresponded to nobox. Bearing in mind that these two genes represented only $18 \%$ of the 11 genes showing Bspecific sequence signatures, it is clear that the transcriptional profile of $\mathrm{B}$ chromosomes is highly biased towards functions dealing with cell division control. It was remarkable that the most actively transcribed Blinked genes showed a full transcript whereas those mostly silenced showed only a partial transcript, suggesting their pseudogenic nature.

Among the transcribed B-linked genes, it was noteworthy that (i) more than $70 \%$ of B-transcripts belonged to a single gene showing a functional role in oogenesis (nobox) in both species (Table S6); (ii) this was found in ovary but not in muscle RNA (Fig. 5); and (iii) for this gene, B-carrying individuals showed more intense transcription for B-linked paralogs than for the standard gene copies residing on the A chromosomes (almost 30fold higher in A. scabripinnis and 7-13-fold in A. paranae) (Table S6). We are thus tempted to speculate that B chromosomes in Astyanax are playing their destiny during oogenesis, like B chromosomes in many other organisms. Whether this implies the existence of $\mathrm{B}$ chromosome drive during female meiosis needs to be clarified by means of inheritance analysis through controlled crosses, a task remaining for future research.

The observed upregulation of the nobox gene might provide a mechanistic explanation to previous results showing an association between $\mathrm{B}$ chromosome presence in A. scabripinnis and sex ratio distortion [54], hermaphroditism [55], or upregulation of the dmrt1 gene [56]. The transcriptional profile of B-linked genes suggests that their expression might affect gonadal development, and in this context, it should also be investigated the possibility that pseudogenic B-transcripts for the amhr2 gene might interfere this process, as this gene has been shown to be a master sex determining in other teleost fish [57]. The analysis of co-expression between the most highly transcribed B-linked gene (nobox) and other genes being crucial for sex and gonadal development (e.g., dmrt1) may help to clarify whether B chromosome presence in this species influences sex determination, as suggested in cichlid fishes [58], and to elucidate under which conditions B-chromosomal effects are apparent. The limitation of B-chromosomal effects to dmrt1 expression in the testis, with no effects in the ovary [56], indicates that other genes, in addition to nobox, might be involved in these effects and/or B chromosome drive. For instance, the 5-fold transcription of the Alt sequence variant for the $m s h 4$ gene (i.e., a pleiotropic gene involved in oogenesis and spermatogenesis), observed in muscle RNA from one A. paranae B-carrying individual, suggests that $\mathrm{B}$-linked genes might play a relevant role in other life cycle stages, apart from oogenesis. On this basis, the apparent absence of the nobox gene in the $\mathrm{B}$ chromosome of $A$. fasciatus might also suggest the importance of other B-linked genes (e.g., msh4) as potential granters of $\mathrm{B}$ chromosome drive, which represents another interesting question to approach in future research.

\section{Conclusions}

In summary, we show here that the similarity in gene content of B chromosomes in four species of fish of the genus Astyanax is correlated with these species' phylogeny and is thus consistent with B chromosome presence in their most recent common ancestor which lived 4 mya. Thus, we demonstrated that B chromosomes can endure through speciation events despite lacking regular pairing and segregation during meiosis. The recent finding that a B-linked gene in Nasonia vitripennis is responsible for $\mathrm{B}$ drive [7] inspires the speculation that B-linked genes in Astyanax, such as nobox, might have helped $\mathrm{B}$ chromosome maintenance for the long timescales shown here. Likewise, as Bchromosomal genes are not fully silenced, the possibility exists that B-derived transcripts provoked gene 
expression changes affecting the species diversification of this genus.

\section{Methods \\ Sampling and determination of B chromosome number}

We analyzed samples from natural populations of $A$. paranae, A. bockmanni, A. fasciatus, and A. scabripinnis (Additional file 1: Table S7). Previous studies showed the presence of $\mathrm{B}$ chromosomes in all these populations $[20,27,59,60]$. The animals were collected in accordance with Brazilian environmental protection legislation (Collection Permission MMA/IBAMA/SISBIO-number 3245) and the procedures for fish sampling, maintenance, and analysis were performed in compliance with the Brazilian College of Animal Experimentation (COBEA) and approved (protocol 504) by the BIOSCIENCE INSTITUTE/UNESP ETHICS COMMITTEE ON THE USE OF ANIMALS (CEUA). The specimens were identified and deposited at the fish collection of the Fish Biology and Genetics Laboratory, Botucatu, São Paulo, Brazil, under the vouchers LBP19572 (A. paranae) and LBP19573 (A. fasciatus). The specimens of $A$. scabripinnis and A. bockmanni were deposited at the Zoology Museum of the State University of Londrina, Londrina, Paraná, Brazil, under the voucher MZUEL 8371 and in the fish collection of Fish Genetics Laboratory, Bauru, São Paulo, Brazil, respectively.

$\mathrm{B}$ chromosome number of all individuals analyzed in this study was determined through cytogenetic analysis following the protocol described by Foresti et al. [61]. Briefly, the animals were treated with an aqueous solution of colchicine $0.025 \%$ during $40 \mathrm{~min}$, anesthetized, and killed, and the chromosomal preparations were obtained from cells of the anterior kidney and gills. Cbanding was performed according to the protocol described by Sumner [62], to improve accuracy in identifying the presence and number of B chromosomes in the samples. Chromosome preparations were stained for 5 min with $5 \%$ Giemsa solution in phosphate buffer $(\mathrm{pH}=$ 6.7). At least ten mitotic metaphase cells were analyzed per specimen. The images were captured with a digital camera (Olympus DP80) attached to an Olympus BX61 epifluorescence photomicroscope, using Image Pro Plus 6.0 software (Media Cybernetics). Image treatment, including optimization of brightness and contrast, was performed using the Adobe Photoshop CS4 program.

\section{Nucleic acid extraction and Illumina sequencing}

We obtained genomic DNA (gDNA) from samples (Additional file 1: Table S8) using the NucleoSpin ${ }^{\circ}$ Tissue Kit (Macherey Nagel) following the manufacturer's instructions. We included a step for RNA removal by adding $20 \mu \mathrm{L}$ of RNAse A $(10 \mathrm{mg} / \mathrm{mL})$ (Invitrogen) per sample and incubating for $5 \mathrm{~min}$ at room temperature.
Samples were run on 1\% agarose gel to check DNA integrity and then used for qPCR and Illumina sequencing experiments. For qPCR, we used DNA from muscle from A. scabripinnis, and liver from A. paranae, A. bockmani, and A. fasciatus species (Additional file 1: Table S8). No heteromorphic sex chromosomes have been reported in the extensive cytogenetic literature of Astyanax species, nor did our analyses reveal the presence of any heteromorphic bivalent in meiosis. Therefore, in absence of information on the possible existence of homomorphic sex chromosomes in these species, the only observable variation in chromosome number, between individuals of any Astyanax species, was due to the presence of B chromosomes. For this reason, we used males and females indistinctly, and muscle or liver for qPCR and ovary, testis, and muscle for RT-qPCR experiments (Additional file 1: Table S8). For Illumina sequencing in A. scabripinnis, we extracted genomic DNA from the muscles of three $\mathrm{OB}$ individuals (one female and two males) and three $1 \mathrm{~B}$ individuals (two females and one male), and they were sequenced using the platform Illumina HiSeq $X$ Ten yielding read lengths of $2 \times 150 \mathrm{bp}$. In $A$. paranae, however, we extracted genomic DNA from the liver of a $0 \mathrm{~B}$ female and a $1 \mathrm{~B}$ female, using Illumina HiSeq2000 with yielded read length of $2 \times 101 \mathrm{bp}$ (Additional file 1: Table S9). These differences between the Illumina platforms were due to their availability when we obtained them. Again, we expect that this has no substantial effect on the final results, since experimental design is homogeneous within every species and we performed the $1 \mathrm{~B}$ and $\mathrm{OB}$ comparison separately in every species.

In each species, the individuals used for RNA extraction were collected on the same day and were kept in a common aquarium. After dissection, tissues were immediately frozen in liquid nitrogen and stored at $70^{\circ} \mathrm{C}$. The analyzed tissues are described in Additional file 1: Table S8. RNA was extracted using the TRIzol ${ }^{\circ}$ Kit (Invitrogen), following the manufacturer's instructions. Subsequently, the samples were treated with DNaseI (Thermo Fisher Scientific) and checked on a $1 \%$ agarose gel and on a 2100 Bioanalyzer (Agilent) equipment. Only RNA samples with A260/280 ratio of 1.8-2.0, A260/230 ratio > 2.0, and RIN $>7$ were used for subsequent analysis. Here we used female RNA for RT-qPCR in A. scabripinnis and A. paranae species (Additional file 1: Table S8). For Illumina sequencing, we used two $0 \mathrm{~B}$ ovary and two $1 \mathrm{~B}$ ovary in A. scabripinnis and three individuals for $\mathrm{OB}$ and $1 \mathrm{~B}$ ovary, and $\mathrm{OB}$ and $1 \mathrm{~B}$ muscle in A. paranae (Additional file 1: Table S9). We focused our expression analysis on the two species where B chromosomes are most easily found, as samples with different number of B chromosomes should be obtained under the same environmental 
conditions in order to avoid gene expression changes due to spatial or temporal differences thus obscuring the differences due to $\mathrm{B}$ chromosome presence. In the two other species, the B chromosomes are in a low proportion of individuals in the natural populations, and to obtain several individuals with B chromosomes requires a great effort and several days of field sampling. The differences in the number of samples were due to budget restrictions. In addition, in A. paranae we decided to obtain samples of a somatic tissue to compare gene expression with gonadal tissues and testing the hypothesis of higher B chromosome impact on gonadal tissues.

We newly sequenced all libraries for the present work, except for the gDNA samples in A. paranae, which were previously sequenced by Silva et al. [41] (Additional file 1: Table S9).

\section{Bioinformatic analysis}

The bioinformatic protocol (Fig. 1) used to select candidate genes present in B chromosomes constitutes a new pipeline called whatGene [63]. Our custom scripts used in this study are freely available in a repository [64]. We first generated independent de novo assemblies of the transcriptomes in A. scabripinnis and A. paranae, separately, using all the RNA-seq libraries, i.e., four and twelve, respectively (Additional file 1: Table S9). We assembled them using the Trinity software v2.1.1 [65], with default options for trimming, in silico normalization and assembly. Then we used Transdecoder v2.0.1 [65] to predict and extract the CDS from the contigs and removed redundancies using CD-HIT v4.6.4 [66] with options "-M 0 -aS 0.8 -c 0.8 -G 0 -g 1". After that, we merged the resulting files from both species into a single reference transcriptome and removed redundancies again with CD-HIT using the same options. Finally, we proceeded to the annotation with Trinotate v3.2.0 (https://trinotate.github.io) and Blast2GO v5.2.5 [67]. Note that the main limitation in mapping genomic reads against a reference transcriptome is that coverage in exon junctions is a bit reduced. However, as we used software supporting partial mappings of the reads, it is not a big problem. Advantages of using a reference transcriptome in case of non-model species with large and unsequenced genomes are that (i) it is more easy to assemble than genomic sequences by lacking introns, (ii) the analysis is focused in the part of the genome with putatively functional roles, and (iii) the interference of repetitive elements on assembling is minimal, as we removed those transcripts showing up to four copies per haploid genome in $\mathrm{OB}$ individuals.

The next step consisted in mapping gDNA reads against the reference transcriptome, using SSAHA2 v2.5.4 [68] with a mapping length of least $40 \mathrm{nt}$ and with a minimum identity of $80 \%$ using the "ssaha2_run_multi.py" script [64]. We then converted CDS coverage to copy number per haploid genome, taking into account library size and that the diploid genome size of A. scabripinnis is 3.74 pg [69]. To calculate the genome size of $1 \mathrm{~B}$ individuals, we estimated the relative size of the $\mathrm{B}$ chromosome on chromosome preparations as $\sim 5 \%$ of A chromosomes per haploid genome (i.e., $0.093 \mathrm{pg}$ ), so the $1 \mathrm{~B}$ genome size would be equal to $3.83 \mathrm{pg}$. We finally converted pg to $\mathrm{Gb}$, considering that $1 \mathrm{pg}$ of DNA corresponds to $0.978 \mathrm{~Gb}$ [70]. The resulting diploid genome sizes for $\mathrm{OB}$ and $\mathrm{BB}$ individuals were 3.658 and $3.749 \mathrm{~Gb}$, respectively. We considered the same values in the case of $A$. paranae, since they are sister species belonging to the same species complex [16].

We extracted coverage information per nucleotide position for all mapped libraries, using the "bam_coverage_join.py" script [64], and then used the "coverage_ graphics.py" script [64] with the "NOPLOT" option to estimate the copy number per haploid genome for every CDS. Next, we discarded, in each species, those contigs that presented less than 0.5 or more than 4 copies per haploid genome, to minimize cases of putative assembly problems or repetitive DNA, respectively. As 1B individuals carry two A chromosome sets plus one B chromosome, and assuming one gene copy per A chromosome and $\mathrm{B}$ chromosome, we calculated the genomic fold change (gFC) in copy number expected between $1 \mathrm{~B}$ and $\mathrm{OB}$ genomes as $\log 2$ of the $1 \mathrm{~B} / \mathrm{OB}$ quotient [i.e., $\log 2(3 /$ $2)=0.585]$. In $A$. scabripinnis, we calculated gFC for each $1 \mathrm{~B}$ individual separately, in reference to the average of copy numbers in the three $\mathrm{OB}$ individuals, and then we performed a first contig selection including all those where $\mathrm{gFC} \geq 0.585$ in all three $1 \mathrm{~B}$ individuals. As a single $1 \mathrm{~B}$ individual was sampled for $A$. paranae, we conservatively selected those contigs with gFC $\geq 1$. Then, we selected annotated contigs, excluding repetitive elements. For these mappings and calculations, we assumed that A and $\mathrm{B}$ chromosome gene copies are paralogs showing highly similar sequence, as previously reported in another B chromosome system [41], so that A- and Bderived reads can map against the same reference sequence.

Some of the selected CDSs in the reference transcriptome that passed this annotation filter were incomplete, as they lacked start and/or stop codons, whereas other CDSs belonged to different regions of the same gene but had been assembled in different contigs. We solved these assembly issues by performing manual curation to get the longest contigs as possible, in the first case, and a single contig per gene in the second case. For this purpose, we searched for their full sequence in the $0 \mathrm{~B}$ de novo transcriptome assemblies generated for each species and also in the combined $\mathrm{OB}$ and $1 \mathrm{~B}$ libraries using 
BLASTN v2.10.0 [71] with default parameters. This strategy yielded a short collection of contigs (in most cases including UTR and CDS regions), which were used as a reference to perform new mappings of gDNA and RNA Illumina reads from different individuals, using SSAHA2 with the same options described above. We processed the resulting mappings by extracting the counts per position with the "bam_coverage_join.py" script [64] and then using the "coverage_graphics.py" script [64] with "PDF" option to get the average coverage per gene and generate coverage plots along every gene in A. scabripinnis. Visual inspection of these coverage plots showed the existence of two types of Bchromosomal genes, i.e., those showing coverage uniformly higher in $1 \mathrm{~B}$ genomes ( $\mathrm{UC}=$ uniform coverage) and those showing higher coverage only in some gene regions $(\mathrm{IC}=$ irregular coverage) (Fig. 4a, Additional file 4: Dataset 3). In IC genes, we identified regions showing high (HC) or low (LC) coverage delimited by abrupt coverage changes. This allowed estimating gene copy numbers separately for $\mathrm{HC}$ and $\mathrm{LC}$ regions for each IC gene, using the "coverage_graphics.py" script [64] with the "NOPLOT" option. HC and LC regions of IC genes where then chosen to perform separate qPCR analysis for genomic overabundance of some of these genes in Bcarrying individuals.

We also searched for B-specific nucleotide variation in A. scabripinnis through SSAHA2 mapping of gDNA and RNA libraries against the manually curated contigs. For this purpose, we merged all mappings from $0 \mathrm{~B}$ gDNA, 1B gDNA, OB RNA, and 1B RNA (i.e., four mapping files in total), using SAMtools (v1.10) [72], and extracted the counts per position for the four nucleotides, including insertions and deletions, using the "bam_var_join.py" script [64]. Then we used the "snp_calling_bchr.py" script [64] to select those SNPs being fixed in the OB gDNA (Ref allele), which showed counts for an alternative allele exclusive of 1B gDNA (Alt allele). Then we filtered out the SNPs showing a lower proportion of Ref than Alt alleles to minimize the frequency of Ref alleles in the B chromosome. Since it is not possible to distinguish between Ref alleles from A and B paralogs, we decided to remove SNPs with a higher proportion of Ref alleles respect to Alt alleles in 1B individuals. In practice, we found that this pattern occurs in those genes showing many copies on the B chromosome, where some B-linked copies have the Ref allele and other Blinked copies have the Alt allele. After that, we extracted the counts for the Ref and Alt alleles for the selected SNPs in every single library from A. scabripinnis and $A$. paranae (gDNA and RNA), first using the "bam_var join.py" script [64] with the 24 libraries, and then the "get_var_library.py" script [64]. To enrich the SNP sample in those conserved between A. scabripinnis and
A. paranae A chromosomes, we removed SNPs with two or more counts for the Alt allele in the $\mathrm{OB} A$. paranae gDNA or RNA. Finally, we considered multiple adjacent missing basepairs were considered as a single mutational event.

To investigate the possible transcription of the paralogous gene copies located on B chromosomes, we scored the number of reads showing the Ref and Alt variants for the 114 SNPs in each RNA Illumina library from both species (12 in A. paranae and 4 in A. scabripinnis). We calculated the quotient between the number of reads scored and transcript length, to normalize among genes. Finally, we calculated the intensity of B chromosome transcription for these genes as the Alt/Ref ratio in B-carrying individuals, as it indicates how many transcripts for a given gene came from the transcription of the paralog copy located on the $\mathrm{B}$ chromosome, compared with those coming from the A chromosomes.

We analyzed the chromosome location of B-linked genes in the $A$. mexicanus genome assembly (NCBI Assembly accession number GCA_000372685.2 [43]) and represented it in a Circos plot v0.69-9 [73]. We note that this reference would be valid only if assuming full synteny with the species sampled here.

\section{Quantitative real-time PCR (qPCR)}

We tested the overabundance of B-linked genes in Bcarrying individuals by means of qPCR on gDNA. For this, we selected 24 genes with $\mathrm{gFC} \geq 0.585$ on $\mathrm{HC}$ regions in all the three $1 \mathrm{~B}$ individuals of $A$. scabripinnis. Then, we designed a single primer pair in genes showing the UC pattern, and two primer pairs (for the $\mathrm{HC}$ and $\mathrm{LC}$ regions) in case of IC genes with Primer3 software [74] (Additional file 1: Table S10). We also included three genes in which contigs did not meet all the criteria (irl1b, lap4a, urok) to explore the validity of the thresholds used (Additional file 2: Dataset 1.7).

Relative quantification (RQ) of the copy number for $B$ chromosome genes was performed using the samples described in Additional file 1: Table S8 by quantitative PCR employing the $2^{-\Delta C t}$ method [75]. Quantitative PCR was performed on QuantStudio ${ }^{\mathrm{ma}} 12 \mathrm{~K}$ Flex RealTime PCR Systems (Thermo Fisher Scientific, USA). The reactions were performed in a final volume of $10 \mu \mathrm{L}$, with $3 \mathrm{ng}$ of gDNA, $5 \mu \mathrm{L}$ of Power SYBR $^{\mathrm{mit}}$ Green PCR Master Mix (Thermo Fisher Scientific, USA), and $1 \mu \mathrm{L}$ of each $5 \mu \mathrm{M}$ primer. Cycle conditions were $95^{\circ} \mathrm{C}$ for $10 \mathrm{~min}$; $45 \mathrm{cycles}$ of $95^{\circ} \mathrm{C}$ for $15 \mathrm{~s}$, and $60^{\circ} \mathrm{C}$ for 1 min. An autosomal single-copy gene, hypoxanthine phosphoribosyltransferase (hprt), was used as reference gene. Target and reference genes were analyzed simultaneously in triplicate for three independent samples. 
The specificity of the PCR products was confirmed by dissociation curve analysis.

In $A$. bockmanni, the gDNA of two $1 \mathrm{~B}$ individuals was exhausted so that qPCR analysis could only be performed on two $1 \mathrm{~B}$ individuals for nine genes and one $1 \mathrm{~B}$ individual for six genes. In the latter case, we considered that these genes were in the $\mathrm{B}$ chromosome if the $1 \mathrm{~B}$ individual showed RQ higher that all B-lacking individuals.

Quantification of expression levels of nobox gene was performed using the RNA samples described in Additional file 1: Table S8, using the same set of primers used for quantification of relative copy number. The primers were not designed to the $\mathrm{B}$-specific sequences, so that they were able to amplify both A and B paralogs. The cDNA for each sample was synthesized using the High-Capacity cDNA Reverse Transcription Kit ${ }^{\circ}$ (Thermo Fisher Scientific, USA) using $100 \mu \mathrm{g}$ per sample of total RNA, following the manufacturer's instructions. The cDNA obtained was diluted in RNase-DNase-free water for a 1:50 working solution. The RT-qPCR reactions followed the same thermocycler parameters used for the qPCR reactions, except for the use of cDNA solution instead of the gDNA. Target and reference genes were analyzed simultaneously in duplicates for two independent samples. The normalized relative expression quantity (NREQ) was determined by the $2^{-\Delta \Delta C t}$ method [76], and nobox expression levels were normalized using hprt as the reference gene, with subsequent calibration to the average expression of the $\mathrm{OB}$ group.

\section{Mitogenome assembly and phylogenetic analyses}

We built a dated mitogenome phylogenetic tree to get an estimate of the age for the main lineages studied in this work. For this purpose, we included all the A. scabripinnis and $A$. paranae Illumina gDNA and RNA libraries used here, i.e., 24 libraries in total. We also used gDNA Illumina libraries from $A$. fasciatus and $A$. bockmanni, obtained by Utsunomia et al. (unpublished). We assembled the mitogenome for these 27 libraries using the NOVOPlasty software (v3.7) [77] using the A. paranae mitogenome (GenBank KX609386.1 [78]) as seed. We also included the $A$. mexicanus mitogenome (GenBank AP011982.1 [79]) as an outgroup. The sequences were aligned using the MAFFT software (v7.450) [80] with "auto" option and removed uninformative positions in the alignment with Gblocks (v0.19b) [81] to exclude the control region which is absent in the RNA libraries. Finally, we built a dated phylogenetic tree using BEAST (v1.10.4) [82]. As calibration points, we used the node separating $A$. mexicanus from the remaining species (11.2 mya) and the node separating $A$. fasciatus and $A$. bockmanni (2 mya), considering molecular dating in Piscor et al. [83]. We launched three independent runs with 100,000,000 generations and sampled trees every 1000 generations. Convergence was checked with Tracer (v1.7.1) [84] and burnin was set to $25 \%$.

\section{Statistical analyses}

Two-group comparisons were performed by the Gardner-Altman estimation plot method devised by Ho et al. [42] following Gardner and Altman's design [85], as implemented in https://www.estimationstats.com/. Non-parametric correlation analysis was performed using Statistica 6.0 (Statsoft, Inc.).

\section{Supplementary Information}

The online version contains supplementary material available at https://doi. org/10.1186/s12915-021-00991-9.

Additional file 1: Table S1. Diversity of B chromosome in the Astyanax genus. $2 \mathrm{n}=$ diploid chromosome number. $\mathrm{Bs}=$ range of $\mathrm{B}$ chromosomes found in each population. $\mathrm{a}=$ acrocentric. $\mathrm{m}=$ metacentric. $\mathrm{sm}=$

submetacentric. st = subtelocentric. $A$. jordani and $A$. mexicanus can be considered synonymous, since both references analyzed the blind tetra fish $[24,25]$. Table S2. Statistics of 21 B-linked genes in A. scabripinnis and A. paranae. Genomic fold change $(\mathrm{gFC})$ was calculated as the $\log _{2}(1 \mathrm{~B} / \mathrm{OB})$ quotient between the mean nucleotide coverages along transcript length. $\mathrm{HC}=$ High coverage region. $\mathrm{LC}=$ Low coverage region. $I C=$ Irregular Coverage. $U C=$ Uniform Coverage. Figures in the "ind. gFC $\geq 0.585$ " column indicates the number of $1 B$ A. scabripinnis individuals which met this condition. In the " $\mathrm{PPCR}$ " columns, 1 indicates validation of gene presence on the B chromosome. Table S3. Validation of B-linked genes by qPCR. Genomic fold change $(\mathrm{gFC})$ was calculated as the $\log _{2}(1 \mathrm{~B} / \mathrm{OB})$ quotient between the mean nucleotide coverages along transcript length. $\mathrm{IC}=$ Irregular Coverage. $\mathrm{UC}=$ Uniform Coverage. $\mathrm{Cl}=$ confidence interval. The blank spaces indicate experiments not performed. In the "Binary information" columns, 1 means qPCR validation. $\mathrm{Asc}=\mathrm{A}$. scabripinnis. $\mathrm{Apa}=\mathrm{A}$. paranae. $\mathrm{Abo}=\mathrm{A}$. bockmanni. $\mathrm{Afa}=$ A. fasciatus. Table S4. Counts of reference (Ref) and alternative (Alt $=B$-specific) variants in all gDNA and RNA libraries analyzed in A. scabripinnnis and A. paranae. Table S5. Nucleotide variation found in the B chromosome gene paralogs of $A$. scabripinnis. To score the number of variants, we distinguished between substitutions (s), deletions (d) or insertions (i) with respect to the A chromosome paralogs. We considered deletions and insertions as a single mutation event when they involved two or more consecutive nucleotides. $\mathrm{dS}=$ number of synonymous substitutions. $\mathrm{dN}=$ number of nonsynonymous substitutions. ps = proportion of variable sites. Table S6. Gene expression profile and transcription intensity of B chromosomes. See Methods for details. Table S7. Localities, diploid chromosome number (2n) and number of samples ( $\mathrm{N}$ ) of the Astyanax individuals analyzed cytogenetically in this study. All populations harbor a large metacentric B chromosome. Table S8. Description of the materials analyzed by quantitative PCR. Table S9. Description of the Illumina-sequenced materials. Table S10. Primers designed in this study for PCR amplification of B-linked genes.

Additional file 2. Dataset 1. Spreadsheet showing the procedure for CDS selection by applying consecutive filters: 1) All contigs showing mappings in gDNA libraries (40,679 contigs), 2a) Contigs with average number of copies, in the OB libraries of A. scabripinnis, ranging between 0.5 and 4 (33,297 contigs), $2 \mathrm{~b}$ ) Contigs with average number of copies in the $\mathrm{OB}$ libraries of $A$. paranae between 0.5 and 4 (32,844 contigs), 3a) Contigs showing genomic fold change due to $B$ chromosome presence $\left[\mathrm{gFC}=\log _{2}(1 \mathrm{~B} / 0 \mathrm{~B})\right]$ higher than 0.585 in at least $1 \mathrm{~B}$ individual of $\mathrm{A}$. scabripinnis (1928 contigs), 3b) Contigs showing genomic fold change due to $B$ chromosome presence $\left[g F C=\log _{2}(1 B / 0 B)\right]$ higher than 1 in the $1 \mathrm{~B}$ individual of $A$. paranae (377 contigs), 4a) Contigs showing genomic fold change due to $\mathrm{B}$ chromosome presence $[\mathrm{gFC}=$ $\left.\log _{2}(1 \mathrm{~B} / 0 \mathrm{~B})\right]$ higher than 0.585 in all the three $1 \mathrm{~B}$ individuals of $A$. scabripinnis (431 contigs), 5a) Contigs of A. scabripinnis annotated from Astyanax 
mexicanus genome excluding repetitive elements (227 contigs), 5b) Contigs of A. paranae annotated from Astyanax mexicanus genome excluding repetitive elements (257 contigs), 6) Combination of $5 \mathrm{a}$ and $5 \mathrm{~b}$ data (450 contigs), 7) qPCR results associated with each contig. Note that the irl1b and lap $4 a$ contigs have $\mathrm{gFC} \geq 0.585$ in only two individuals of $A$. scabripinnis, while the urok gene meets this criterion in only one individual of this species, but the three genes have average gFC value about 0.65 . Also note that the gFC of the urok gene in A. paranae is close to the threshold used.

Additional file 3: Dataset 2. Relative transcription levels for the nobox gene in B-carrying and B-lacking individuals. NREQ $=$ Normalized relative expression quantity. (XLS $37 \mathrm{~kb}$ )

Additional file 4: Dataset 3. Coverage levels of the 21 protein-coding genes found in the A. scabripinnis and A. paranae B chromosomes. gDNA coverage is shown as number of copies. Additionally, we add a track showing the position of the B-specific SNPs found in the A. scabripinnis libraries. The dotted lines delimit the CDS region and the shaded zones indicate the regions amplified in the GPCR experiments. The coverage pattern attributed to each gene can be found in the Table 1 .

\section{Acknowledgements}

We are thankful Renato Devidé for his technical assistance and Rafael Henrique Nóbrega and Maeli Dal Pai Silva for the use of their laboratory equipment and Judith Mank for the useful feedback to the manuscript.

\section{Authors' contributions}

Conceptualization: DMZAS, FJRR, RU, CO, FPF, RFA, JPMC, FF, JPMC; experimental design: DMZAS, FJRR, RU, JPC, PPF, RFC, AS, CO, FF, JPMC; collected samples: DMZAS, RU, JPC, PPF, DH, FPF, RFA, cytogenetics analyses: DMZAS, JPC, DH, CO, FPF, RFA, FF; qPCR analyses: DMZAS, JCP, PPF, RFC, DH, FPF, RFA, FF, JPMC; bioinformatic analyses: DMZAS, FJRR, RU, MMP, AS, FF, JPMC, contributed with reagents/materials/analysis tools: DMZAS, RU, RFC, $\mathrm{DH}, \mathrm{CO}, \mathrm{FPF}, \mathrm{RFA}$, FF, JPMC. All authors read and approved the manuscript.

\section{Authors' information}

FJRR and DMZAS are co-first authors.

ORCIDs for some of the authors: DMZAS (0000-0002-2610-2254), FJRR (00000002-5391-301X), RU (0000-0003-4565-6065), JPC (0000-0003-0887-1081), PPF (0000-0003-0649-8279), RFC (0000-0002-4901-7714), DH (0000-0002-88082498), AS (0002-8979-9992), CO (0000-0002-7010-8880), FPF (0000-0001-88453845), RFA (0000-0002-2528-9846) and JPMC (0000-0002-2507-9814). Twitter account for some of the authors: DMZAS (@duilio_sil), FJRR (@fjruizruano), RU (@RUtsunomia), MMP (@maria_marpe), PPF (@PaccielliPaula),RFC (@rcarvalho_7), and AS (@alexander_suh).

\section{Funding}

This study was supported by grants from Fundação de Amparo à Pesquisa do Estado de São Paulo (FAPESP) (grants 2014/09634-5 to FF; 2013/24143-5, 2017/22447-8 to DMZAS and 2018/20610-1, 2016/09204-6, 2014/26508-3 to CO), Coordenação de Aperfeiçoamento de Pessoal de Nível Superior (CAPES), Conselho Nacional de Desenvolvimento Científico e Tecnológico (CNPq) (grant 306054/2006-0 to CO), Spanish Secretaría de Estado de Investigación, Desarrollo e Innovación (CGL2015-70750-P), and was partially performed by FEDER funds. FJRR was also supported by a Junta de Andalucía fellowship (Spain), a postdoctoral fellowship from Sven och Lilly Lawskis fond (Sweden) and a Marie Skłodowska-Curie Individual Fellowship (grant agreement 875732, European Commission). Open Access funding provided by Uppsala University.

\section{Availability of data and materials}

The Illumina libraries used for this article are available in the Sequence Read Archive (SRA) under Bioprojects PRJNA383714 [86], PRJNA560500 [87], PRJNA560501 [88] and PRJNA560502 [89] (see Additional file 1: Table S9 for details). Main data generated or analyzed during this study are included in this published article and its supplementary information files. The remaining datasets can be requested to the corresponding authors.

\section{Declarations}

Ethics approval and consent to participate Not applicable.

\section{Consent for publication}

Not applicable.

\section{Competing interests}

The authors declare no competing interests.

\section{Author details}

${ }^{1}$ Departamento de Biologia Estrutural e Funcional, Instituto de Biociências de Botucatu, Universidade Estadual Paulista, UNESP, Distrito de Rubião Junior, Botucatu, SP 18618-970, Brazil. '2Department of Organismal Biology Systematic Biology, Evolutionary Biology Centre, Uppsala University, SE-752 36 Uppsala, Sweden. ${ }^{3}$ Departamento de Genética, Universidad de Granada, 18071 Granada, Spain. ${ }^{4}$ School of Biological Sciences, University of East Anglia, Norwich Research Park, Norwich NR4 7TU, UK. ${ }^{5}$ Departamento de Genética, Instituto de Ciências Biológicas e da Saúde, ICBS, Universidade Federal Rural do Rio de Janeiro, Seropédica, RJ 23897-000, Brazil.

${ }^{6}$ Departamento de Ciências Biológicas, Faculdade de Ciências, Universidade Estadual Paulista, UNESP, Campus de Bauru, Bauru, SP 17033-360, Brazil. ${ }^{7}$ Departamento de Genética e Evolução, Universidade Federal de São Carlos, UFSCAR, São Carlos, SP 13565-905, Brazil. 'Departamento de Biologia Estrutural, Molecular e Genética, Universidade Estadual de Ponta Grossa, UEPG, Ponta Grossa, PR 84030-900, Brazil. ' Departamento de Imunologia, Instituto de Ciências Biomédicas, Universidade de São Paulo, USP, São Paulo, SP 05508-900, Brazil. ${ }^{10}$ Centro de Aquicultura, Universidade Estadual Paulista, UNESP, Campus Jaboticabal, Jaboticabal, SP 14884-900, Brazil.

Received: 7 September 2020 Accepted: 24 February 2021 Published online: 19 March 2021

\section{References}

1. Östergren G. Parasitic nature of extra fragment chromosomes. Bot Not. 1945;2:157-63.

2. Nur U. A supernumerary chromosome with an accumulation mechanism in the lecanoid genetic system. Chromosoma. 1962;13:249-71.

3. Martis MM, Klemme S, Banaei-Moghaddam AM, Blattner FR, Macas J, Schmutzer T, et al. Selfish supernumerary chromosome reveals its origin as a mosaic of host genome and organellar sequences. Proc Natl Acad Sci U S A. 2012;109:13343-6.

4. Valente GT, Conte MA, Fantinatti BE, Cabral-de-Mello DC, Carvalho RF, Vicari $M R$, et al. Origin and evolution of B chromosomes in the cichlid fish Astatotilapia latifasciata based on integrated genomic analyses. Mol Biol Evol. 2014;31:2061-72.

5. Makunin AI, Dementyeva PV, Graphodatsky AS, Volobouev VT, Kukekova AV, Trifonov VA. Genes on B chromosomes of vertebrates. Mol Cytogenet. 2014;7:99.

6. Navarro-Domínguez B, Ruiz-Ruano FJ, Cabrero J, Corral JM, López-León MD, Sharbel TF, et al. Protein-coding genes in B chromosomes of the grasshopper Eyprepocnemis plorans. Sci Rep. 2017;7:45200.

7. Benetta E, Antoshechkin I, Yang T, Nguyen HQ, Ferree PM, Akbari OS. Genome elimination mediated by gene expression from a selfish chromosome. Sci Adv. 2020;6:eaaz9808.

8. Han Y, Liu X, Benny U, Corby Kistler H, VanEtten HD. Genes determining pathogenicity to pea are clustered on a supernumerary chromosome in the fungal plant pathogen Nectria haematococca. Plant J. 2001;25:305-14.

9. Nokkala S, Kuznetsova V, Maryańska-Nadachowska A. Achiasmate segregation of a $B$ chromosome from the $X$ chromosome in two species of psyllids (Psylloidea, Homoptera). Genetica. 2000;108:181-9.

10. Nokkala S, Grozeva S, Kuznetsova V, Maryanska-Nadachowska A. The origin of the achiasmatic XY sex chromosome system in Cacopsylla peregrina (Frst.) (Psylloidea, Homoptera). Genetica. 2003;119:327-32.

11. Kinsella CM, Ruiz-Ruano FJ, Dion-Côté AM, Charles AJ, Gossmann TI, Cabrero $J$, et al. Programmed DNA elimination of germline development genes in songbirds. Nat Commun. 2019;10:5468.

12. Vujošević M, Blagojević J. B chromosomes in populations of mammals. Cytogenet Genome Res. 2004;106:247-56.

13. Ornelas-García CP, Domínguez-Domínguez O, Doadrio I. Evolutionary history of the fish genus Astyanax Baird \& Girard (1854) (Actinopterygii, Characidae) in Mesoamerica reveals multiple morphological homoplasies. BMC Evol Biol. 2008:8:340.

14. Fricke R, Eschmeyer WN, Van der Laan R. Catalog of fishes: genera, species, references. California Academy of Sciences, San Francisco, CA, USA. http:// 
researcharchive.calacademy.org/research/ichthyology/catalog/fishcatmain.a sp (2018). Accessed 15 Oct 2020.

15. Rossini BC, Oliveira CAM, Melo FAGD, Bertaco VDA, Astarloa JMDD, Rosso J, et al. Highlighting Astyanax species diversity through DNA barcoding. PLoS One. 2016;11:e0167203.

16. Moreira-Filho O, Bertollo LAC. Astyanax scabripinnis (Pisces, Characidae): a species complex. Brazil J Genet. 1991;14:331-57.

17. Hashimoto DT, Gonçalves VR, Bortolozzi J, Foresti F, Porto-Foresti F. First report of a $\mathrm{B}$ chromosome in a natural population of Astyanax altiparanae (Characiformes, Characidae). Genet Mol Biol. 2008;31:275-8.

18. Hashimoto DT, Ferguson-Smith MA, Rens W, Foresti F, Porto-Foresti F. Chromosome mapping of $\mathrm{H} 1$ histone and $5 \mathrm{~S}$ rRNA gene clusters in three species of Astyanax (Teleostei, Characiformes). Cytogenet Genome Res. 2011;134:64-71.

19. Daniel SN, Penitente M, DMZDA S, Hashimoto DT, Ferreira DC, Foresti F, et al. Organization and chromosomal distribution of histone genes and transposable Rex elements in the genome of Astyanax bockmanni (Teleostei, Characiformes). Cytogenet Genome Res. 2015;146:311-8.

20. Silva DMZDA, Daniel SN, Camacho JPM, Utsunomia R, Ruiz-Ruano FJ, Penitente $\mathrm{M}$, et al. Origin of $\mathrm{B}$ chromosomes in the genus Astyanax (Characiformes, Characidae) and the limits of chromosome painting. Mol Gen Genomics. 2016;291:1407-18.

21. Ahmad SF, Jehangir M, Cardoso AL, Wolf IR, Margarido VP, Cabral-de-Mello DC, et al. B chromosomes of multiple species have intense evolutionary dynamics and accumulated genes related to important biological processes. BMC Genomics. 2020;21:656.

22. Torres-Mariano AR, Morelli S. B chromosomes in a population of Astyanax eigenmanniorum (Characiformes, Characidae) from the Araguari River basin (Uberlândia, MG, Brazil). Genet Mol Biol. 2008;31:246-9.

23. Santos LP, Castro JP, Francisco CM, Vicari MR, de Almeida MC, Goll LG. Cytogenetic analysis in the neotropical fish Astyanax goyacensis Eigenmann, 1908 (Characidae, incertae sedis): karyotype description and occurrence of B microchromosomes. Mol Cytogenet. 2013;6:48.

24. Silva DMZDA, Utsunomia R, Pansonato-Alves JC, Oliveira C, Foresti F. Chromosomal mapping of repetitive DNA sequences in five species of Astyanax (Characiformes, Characidae) reveals independent location of U1 and U2 snRNA sites and association of U1 snRNA and 5 S rDNA. Cytogenet Genome Res. 2015:146:144-52.

25. Kavalco KF, Almeida-Toledo LFD. Molecular cytogenetics of blind Mexican tetra. Zebrafish. 2007:4:103-11.

26. Maistro EL, Foresti F, Oliveira C, Almeida-Toledo LFD. Occurrence of macro B chromosomes in Astyanax scabripinnis paranae (Pisces, Characiformes, Characidae). Genetica. 1992;87:101-6.

27. Maistro EL, Foresti F, Oliveira C. New occurrence of a macro B-chromosome in Astyanax scabripinnis paranae (Pisces, Characiformes, Characidae). Braz J Genet. 1994;17:153-6.

28. Silva DMZDA, Pansonato-Alves JC, Utsunomia R, Araya-Jaime C, Ruiz-Ruano FJ, Daniel SN, et al. Delimiting the origin of a B chromosome by FISH mapping, chromosome painting and DNA sequence analysis in Astyanax paranae (teleostei, characiformes). PLoS One. 2014;9:e94896.

29. Salvador LB, Moreira-Filho O. B chromosomes in Astyanax scabripinnis (Pisces, Characidae). Heredity. 1992;69:50-6.

30. Rocon-Stange EA, Almeida-Toledo LFD. Supernumerary B chromosomes restricted to males in Astyanax scabripinnis (Pisces, Characidae). Rev Bras Genét. 1993;16:601-15

31. Maistro EL, Lúcia Dias A, Foresti F, Oliveira C, Filho OM. Natural triploidy in Astyanax scabripinnis (Pisces, Characidae) and simultaneous occurrence of macro B-chromosomes. Caryologia. 1994;47:233-9.

32. Souza IL, Moreira-Filho O. Cytogenetic diversity in the Astyanax scabripinnis species complex (Pisces, Characidae) I. allopatric distribution in a small stream. Cytologia. 1995;60:1-11.

33. Mizoguchi SMHN, Martins-Santos IC. Macro- and microchromosomes B in females of Astyanax scabripinnis (Pisces, Characidae). Hereditas. 1997;127: 249-53.

34. Araujo ACS, Morelli S. Estudo cariotípico da população de Astyanax scabripinnis (Pisces, Characidae) da nascente do córrego Jataí. UberlândiaMG Genet Mol Biol. 2000;23:60.

35. Néo DM, Moreira Filho O, Camacho JPM. Altitudinal variation for B chromosome frequency in the characid fish Astyanax scabripinnis. Heredity 2000;85:136-41.
36. Alves AL, Martins-Santos IC. Cytogenetics studies in two populations of Astyanax scabripinnis with $2 \mathrm{n}=48$ chromosomes (Teleostei, Characidae). Cytologia. 2002;67:117-22.

37. Ferro DAM, Moreira-Filho O, Bertollo LAC. B chromosome polymorphism in the fish, Astyanax scabripinnis. Genetica. 2003;119:147-53.

38. Fernandes CA, Martins-Santos IC. Sympatric occurrence of three cytotypes and four morphological types of B chromosomes of Astyanax scabripinnis (Pisces, Characiformes) in the river Ivaí Basin, state of Paraná, Brazil. Genetica. 2005;124:301-6.

39. Moreira-Filho O, Fenocchio AS, Pastori MC, Bertollo LAC. Occurrence of a metacentric macrochromosome $B$ in different species of the genus Astyanax (Pisces, Characidae, Tetragonopterinae). Cytologia. 2001:66:59-64.

40. Fazoli LC, da Silva VDAB, de Brito Portela-Castro AL, Júnior HFJ. Chromosome characterization of Astyanax sp B (Characidae, Tetragonopterinae), an endemic species of the Iguaçu River, Paraná, Brazil. Cytologia. 2003;68:389-94.

41. Silva DMZDA, Utsunomia R, Ruiz-Ruano FJ, Daniel SN, Porto-Foresti F, Hashimoto DT, et al. High-throughput analysis unveils a highly shared satellite DNA library among three species of fish genus Astyanax. Sci Rep. 2017:7:12726.

42. Ho J, Tumkaya T, Aryal S, Choi H, Claridge-Chang A. Moving beyond P values: data analysis with estimation graphics. Nat Methods. 2019;16:565-6.

43. McGaugh SE, Gross JB, Aken B, Blin M, Borowsky R, Chalopin D, et al. The cavefish genome reveals candidate genes for eye loss. Nat Commun. 2014:5:5307.

44. Perfectti $\mathrm{F}$, Werren $\mathrm{JH}$. The interspecific origin of $\mathrm{B}$ chromosomes: experimental evidence. Evolution. 2001:55:1069-73.

45. McAllister BF, Werren JH. Hybrid origin of a B chromosome (PSR) in the parasitic wasp Nasonia vitripennis. Chromosoma. 1997;106:243-53.

46. Lamatsch DK, Nanda I, Schlupp I, Epplen JT, Schmid M, Schartl M. Distribution and stability of supernumerary microchromosomes in natural populations of the Amazon molly, Poecilia formosa. Cytogenet Genome Res. 2004;106:189-94.

47. Tosta VC, Marthe JB, Tavares MG, Fernandes-Salomão TM, Pompolo SG, Recco-Pimentel SM, et al. Possible introgression of B chromosomes between bee species (genus Partamona). Cytogenet Genome Res. 2014; 144:220-6.

48. Torgasheva AA, Malinovskaya LP, Zadesenets KS, Karamysheva TV, Kizilova EA, Akberdina EA, et al. Germline-restricted chromosome (GRC) is widespread among songbirds. Proc Natl Acad Sci U S A. 2019;116:11845-50.

49. Oliveira C, Rodrigues Saboya SM, Foresti F, Senhorini JA, Bernardino G. Increased B chromosome frequency and absence of drive in the fish Prochilodus lineatus. Heredity. 1997;79:473-6.

50. Voltolin TA, Senhorini JA, Foresti F, Bortolozzi J, Porto-Foresti F. Intraspecific crosses resulting in the first occurrence of eight and nine B chromosomes in Prochilodus lineatus (Characiformes, Prochilodontidae). Genet Mol Biol. 2011;34:220-4.

51. Penitente M, Voltolin TA, Senhorini JA, Bortolozzi J, Foresti F, Porto-Foresti F. Transmission rate variation among three $B$ chromosome variants in the fish Prochilodus lineatus (Characiformes, Prochilodontidae). An Acad Bras Cienc. 2013;85:1371-7.

52. Nanda I, Schlupp I, Lamatsch DK, Lampert KP, Schmid M, Schartl M. Stable inheritance of host species-derived microchromosomes in the gynogenetic fish Poecilia formosa. Genetics. 2007:177:917-26.

53. Clark FE, Kocher TD. Changing sex for selfish gain: B chromosomes of Lake Malawi cichlid fish. Sci Rep. 2019:9:20213.

54. Vicente VE, Moreira-Filho O, Camacho JPM. Sex-ratio distortion associated with the presence of a B chromosome in Astyanax scabripinnis (Teleostei, Characidae). Cytogenet Cell Genet. 1996;74:70-5.

55. Cornelio D, Castro JP, Santos MH, Vicari MR, de Almeida MC, Moreira-Filho $\mathrm{O}$, et al. Hermaphroditism can compensate for the sex ratio in the Astyanax scabripinnis species complex (Teleostei: Characidae): expanding the B chromosome study model. Rev Fish Biol Fish. 2017;27:681-9.

56. Castro JP, Hattori RS, Yoshinaga TT, Silva DM, Foresti F, Santos MH, et al. Differential expression of dmrt1 in Astyanax scabripinnis (Teleostei, Characidade) is correlated with B chromosome occurrence. Zebrafish. 2018; 16:182-8

57. Kamiya T, Kai W, Tasumi S, Oka A, Matsunaga T, Mizuno N, et al. A trans-species missense SNP in Amhr2 is associated with sex 
determination in the tiger pufferfish, Takifugu rubripes (fugu). PLoS Genet. 2012;8:e1002798.

58. Yoshida K, Terai Y, Mizoiri S, Aibara M, Nishihara H, Watanabe M, et al. B chromosomes have a functional effect on female sex determination in Lake Victoria cichlid fishes. PLoS Genet. 2011;7:e1002203.

59. Castro JP, Moura MO, Moreira-Filho O, Shibatta OA, Santos MH, Nogaroto V, et al. Diversity of the Astyanax scabripinnis species complex (Teleostei: Characidae) in the Atlantic Forest, Brazil: species limits and evolutionary inferences. Rev Fish Biol Fish. 2014;25:231-44.

60. Daniel SN, Penitente M, Hashimoto DT, Silva DMZDA, Foresti F, Porto-Foresti F. New insights into karyotypic relationships among populations of Astyanax bockmanni (Teleostei, Characiformes) of different watersheds. Zebrafish. 2015;12:181-8

61. Foresti F, Almeida-Toledo LFD, Toledo-Filho SA. Polymorphic nature of nucleolus organizer regions in fishes. Cytogenet Cell Genet. 1981;31:137-44.

62. Sumner AT. A simple technique for demonstrating centromeric heterochromatin. Exp Cell Res. 1972;75:304-6.

63. Ruiz-Ruano FJ, Navarro-Domínguez B, López-León MD, Cabrero J, Camacho JPM. Evolutionary success of a parasitic $B$ chromosome rests on gene content. Preprint at bioRxiv https://doi.org/10.1101/683417 (2019).

64. Ruiz-Ruano FJ. whatGene repository. https://github.com/fjruizruano/wha tGene (2020). Accessed 22 June 2020.

65. Haas BJ, Papanicolaou A, Yassour M, Grabherr M, Blood PD, Bowden J, et al. De novo transcript sequence reconstruction from RNA-seq using the trinity platform for reference generation and analysis. Nat Protoc. 2013;8:1494-512.

66. Li W, Godzik A. Cd-hit: a fast program for clustering and comparing large sets of protein or nucleotide sequences. Bioinformatics. 2006;22:1658-9.

67. Conesa A, Götz S, García-Gómez JM, Terol J, Talón M, Robles M. Blast2GO: a universal tool for annotation, visualization and analysis in functional genomics research. Bioinformatics. 2005;21:3674-6.

68. Ning Z, Cox AJ, Mullikin JC. SSAHA: a fast search method for large DNA databases. Genome Res. 2001;11:1725-9.

69. Carvalho ML, Oliveira C, Foresti F. Nuclear DNA content of thirty species of Neotropical fishes. Genet Mol Biol. 1998;21:1.

70. Dolezel J, Bartos J, Voglmayr H, Greilhuber J. Nuclear DNA content and genome size of trout and human. Cytom Part A. 2003;51:127-8.

71. Altschul SF, Gish W, Miller W, Myers EW, Lipman DJ. Basic local alignment search tool. J Mol Biol. 1990;215:403-10.

72. Li H, Handsaker B, Wysoker A, Fennell T, Ruan J, Homer N, et al. The sequence alignment/map format and SAMtools. Bioinformatics. 2009;25:2078-9.

73. Krzywinski M, Schein J, Birol I, Connors J, Gascoyne R, Horsman D, et al. Circos : an information aesthetic for comparative genomics. Genome Res. 2009;19:1639-45.

74. Untergasser A, Cutcutache I, Koressaar T, Ye J, Faircloth BC, Remm M, et al. Primer3-new capabilities and interfaces. Nucleic Acids Res. 2012;40:e115.

75. Bel Y, Ferré J, Escriche B. Quantitative real-time PCR with SYBR green detection to assess gene duplication in insects: study of gene dosage in Drosophila melanogaster (Diptera) and in Ostrinia nubilalis (Lepidoptera). BMC Res Notes. 2001;4:84.

76. Livak KJ, Schmittgen TD. Analysis of relative gene expression data using real-time quantitative PCR and the $2^{-\Delta \Delta C T}$ method. Methods. 2011;25:402-8.

77. Dierckxsens N, Mardulyn P, Smits G. NOVOPlasty: de novo assembly of organelle genomes from whole genome data. Nucleic Acids Res. 2017;45:e18

78. Silva DMZDA, Utsunomia R, Ruiz-Ruano FJ, Oliveira C, Foresti F. The complete mitochondrial genome sequence of Astyanax paranae (Teleostei: Characiformes). Mitochondrial DNA Part B Resour. 2016;1:586-7.

79. Nakatani M, Miya M, Mabuchi K, Saitoh K, Nishida M. Evolutionary history of Otophysi (Teleostei), a major clade of the modern freshwater fishes: Pangaean origin and Mesozoic radiation. BMC Evol Biol. 2011;11:177.

80. Katoh K, Standley DM. MAFFT multiple sequence alignment software version 7: improvements in performance and usability. Mol Biol Evol. 2013; 30:772-80

81. Talavera G, Castresana J. Improvement of phylogenies after removing divergent and ambiguously aligned blocks from protein sequence alignments. Syst Biol. 2007;56:564-77.

82. Drummond AJ, Rambaut A. BEAST: Bayesian evolutionary analysis by sampling trees. BMC Evol Biol. 2007;7:214.

83. Piscor D, Pozzobon APB, Fernandes CA, Centofante L, Parise-Maltempi PP. Molecular clock as insight to estimate the evolutionary history and times of divergence for 10 nominal Astyanax species (Characiformes, Characidae): an evolutionary approach in species with $2 n=36,46,48$, and 50 chromosomes. Zebrafish. 2019;16:98-105.

84. Rambaut A, Drummond AJ, Xie D, Baele G, Suchard MA. Posterior summarization in Bayesian phylogenetics using tracer 1.7. Syst Biol. 2018:67:901-4.

85. Gardner MJ, Altman DG. Confidence intervals rather than P values: estimation rather than hypothesis testing. Br Med J. 1986;292:746-50.

86. Silva MDZA, Utsunomia R, Ruiz-Ruano FJ, Daniel SN, Porto-Foresti F, Hashimoto DT, et al. High throughput sequencing of Astyanax paranae. 2017. https://www.ncbi.nlm.nih.gov/bioproject/PRJNA383714.

87. Silva MDZA, Ruiz-Ruano FJ, Utsunomia R, Martín-Peciña M, Pena Castro J, Paccielli Freire $\mathrm{P}$, et al. Genomic sequencing of Astyanax scabripinnis $\mathrm{OB}$ and 1B. 2019. https://www.ncbi.nlm.nih.gov/bioproject/PRJNA560500.

88. Silva MDZA, Ruiz-Ruano FJ, Utsunomia R, Martín-Peciña M, Pena Castro J, Paccielli Freire $P$, et al. Transcriptomic sequencing of Astyanax paranae OB and 1B. 2019. https://www.ncbi.nlm.nih.gov/bioproject/PRJNA560501.

89. Silva MDZA, Ruiz-Ruano FJ, Utsunomia R, Martín-Peciña M, Pena Castro J, Paccielli Freire $P$, et al. Transcriptomic sequencing of Astyanax scabripinnis OB and 1B. 2019. https://www.ncbi.nlm.nih.gov/bioproject/PRJNA560502.

\section{Publisher's Note}

Springer Nature remains neutral with regard to jurisdictional claims in published maps and institutional affiliations.
Ready to submit your research? Choose BMC and benefit from:

- fast, convenient online submission

- thorough peer review by experienced researchers in your field

- rapid publication on acceptance

- support for research data, including large and complex data types

- gold Open Access which fosters wider collaboration and increased citations

- maximum visibility for your research: over $100 \mathrm{M}$ website views per year

At BMC, research is always in progress.

Learn more biomedcentral.com/submissions 